\title{
A novel anti-slip control approach for railway vehicles with traction based on adhesion estimation with swarm intelligence
}

\author{
Abdulkadir Zirek ${ }^{1,2}$ (D) Altan Onat ${ }^{2,3}$
}

Received: 20 May 2020/Revised: 20 October 2020/Accepted: 21 October 2020/Published online: 24 November 2020

(C) The Author(s) 2020

\begin{abstract}
Anti-slip control systems are essential for railway vehicle systems with traction. In order to propose an effective anti-slip control system, adhesion information between wheel and rail can be useful. However, direct measurement or observation of adhesion condition for a railway vehicle in operation is quite demanding. Therefore, a proportional-integral controller, which operates simultaneously with a recently proposed swarm intelligencebased adhesion estimation algorithm, is proposed in this study. This approach provides determination of the adhesion optimum on the adhesion-slip curve so that a reference slip value for the controller can be determined according to the adhesion conditions between wheel and rail. To validate the methodology, a tram wheel test stand with an independently rotating wheel, which is a model of some low floor trams produced in Czechia, is considered. Results reveal that this new approach is more effective than a conventional controller without adhesion condition estimation.
\end{abstract}

Keywords Adhesion estimation - Traction control A Antislip control · Railway vehicles · Roller-rigs · Swarm intelligence

Abdulkadir Zirek

azirek@eskisehir.edu.tr

1 Department of Transport Means and Diagnostics, Faculty of Transport Engineering, University of Pardubice, Pardubice, Czechia

2 Electrical and Electronics Engineering Department, Engineering Faculty, Eskisehir Technical University, Iki Eylul Campus, 26555 Eskisehir, Turkey

3 School of Engineering, Stephenson Building, Newcastle University, Newcastle upon Tyne NE1 7RU, UK

\section{List of symbols}

$s \quad$ Slip (creepage)

$s_{i} \quad$ Slip (creepage) output of each model $i=1,2, \ldots, n$

$s_{\text {ref }} \quad$ Reference slip for the controller

$T_{\text {cont }} \quad$ Torque output of the slip controller applied to the vehicle wheel (test stand)

$\omega_{\mathrm{r}} \quad$ Roller angular speed

$\omega_{\mathrm{w}} \quad$ Wheel angular speed

$\hat{\omega}_{\mathrm{r}_{0}} \quad$ Initial velocity estimate for the roller angular speed

$\hat{\omega}_{\mathrm{w}_{0}} \quad$ Initial velocity estimate for the wheel angular speed

$\hat{f_{0}} \quad$ Maximum friction coefficient estimate of the estimator

$\hat{f_{0}} \quad$ Maximum friction coefficient estimate of each model $i=1,2, \ldots, n$

$F_{x_{i}} \quad$ Longitudinal creep force output of each model $i=1,2, \ldots, n$

a Contact patch ellipse semi-axis length

$b \quad$ Contact patch ellipse semi-axis width

$T_{\mathrm{a}} \quad$ Torque exerted by asynchronous motor

$T_{\mathrm{p}} \quad$ Torque exerted by permanent magnet synchronous motor

$r_{\mathrm{W}} \quad$ Wheel radius

$r_{\mathrm{r}} \quad$ Roller radius

$J_{\mathrm{r}} \quad$ Total moment of inertia of the roller

$J_{\mathrm{w}} \quad$ Total moment of inertia of the wheel

$i_{d}, i_{q} \quad d$ - and $q$-axis components of stator current

$V_{d}, V_{q} \quad d$ - and $q$-axis components of stator voltage

$L_{d}, L_{q} \quad d$ - and $q$-axis stator self-inductances

$R_{\mathrm{S}} \quad$ Resistance of stator windings

$\varphi \quad$ Flux induced by permanent magnet synchronous motor 
$\omega_{\mathrm{e}} \quad$ Electrical speed of the rotor of permanent magnet synchronous motor

$p \quad$ Number of pole pairs for the permanent magnet synchronous motor

$\theta_{\mathrm{e}} \quad$ Electrical position of the rotor of permanent magnet synchronous motor

$T_{\mathrm{p}}^{*} \quad$ Reference control torque ( $T_{\text {cont }}$ in Figs. 2,3$)$

$i_{q}^{*} \quad$ Reference torque current component

$i_{a}^{*}, i_{b}^{*}, i_{c}^{*}$ Three phase current references for $a, b, c$, phases

$i_{a}, i_{b}, i_{c} \quad$ Three phase currents for $a, b, c$, phases

$\omega_{\text {syn }} \quad$ Synchronous speed of the asynchronous motor

$s_{\mathrm{a}} \quad$ Slip of the asynchronous motor

$V_{\text {Th }} \quad$ Thevenin equivalent circuit voltage

$R_{\mathrm{Th}} \quad$ Thevenin equivalent circuit resistance

$X_{\mathrm{Th}} \quad$ Thevenin equivalent circuit reactance

$R_{2}^{\prime} \quad$ Rotor resistance referred to the primary side

$X_{2}^{\prime} \quad$ Rotor reactance referred to the primary side

$f_{0} \quad$ Maximum (static) friction of coefficient

$f \quad$ Variable friction of coefficient

A Ratio of coefficient of friction limits $\left(\frac{f_{\infty}}{f_{0}}\right)$

$B \quad$ Coefficient of exponential decrease

$w \quad$ Slip speed of the wheel

$\varepsilon \quad$ Scaled slip

$k_{\text {red }} \quad$ Reduction factor of the brush contact model

$K \quad$ Tangential stiffness of the contact between surface layers

$p_{\max } \quad$ Maximum Hertzian pressure at contact

$\mu \quad$ Coefficient of adhesion

$K_{\mathrm{p}} \quad$ Proportional gain of the controller

$K_{\mathrm{i}} \quad$ Integral gain of the controller

$e \quad$ Slip error

$s_{\text {act }} \quad$ Actual (measured) wheel slip

$T_{\text {ref }}^{*} \quad$ Output torque request of the proportionalintegral controller

$T_{\text {driver }} \quad$ Driver torque request

$J \quad$ Cost function

$V_{i} \quad$ Velocity of the each particle (i.e. model) of the estimator $i=1,2, \ldots, n$

$\omega \quad$ Inertia weight of the estimator

$c \quad$ Acceleration coefficient of the estimator

$\hat{f}_{0_{\text {best }}} \quad$ Best maximum friction coefficient estimate of the models

$\omega_{\min } \quad$ Minimum inertia weight of the estimator

$\omega_{\max } \quad$ Maximum inertia weight of the estimator

$N_{\mathrm{i}} \quad$ Maximum iteration number for inertia weight calculation

$k \quad$ Iteration index

$V_{\min } \quad$ Minimum velocity limit for each particle

$V_{\max } \quad$ Maximum velocity limit for each particle

\section{Introduction}

Recently, the locomotive manufacturers have started to produce more powerful AC traction technologies for the heavy haul locomotives. However, the traction performance of the haul locomotives is limited with the adhesion condition between the wheel and the rail. Adhesion is known to be the key element for the determination of the optimal traction performance. Moreover, the comfort of the passengers, safety of the goods and energy management of the vehicles are directly affected by the adhesion condition.

As it is illustrated in Fig. 1 that the slip curve has a nonlinear characteristic. The area on the left side of the peak of the slip curve is called adhesion zone and the area on the right side of the peak is the slip zone. The adhesion zone is the stable part of the curve, and adhesion increases when the wheel slip increases. On the other hand, the slip zone is non-stable part of the curve, and adhesion decreases when the wheel slip increases. Most of the wheel slip control methods aim to keep the slip in the stable part of the curve. While the aim of the optimization-based methods is to control the slip towards the peak of the curve where the maximum traction effort is achieved [1]. Therefore, in this study, we implemented a method to control the wheel slip towards the peak of the slip curve. The operation zone of the controllers is limited with the stable and the unstable parts of the slip curve near the maximum point [2]. The behaviour of the slip curve depends on two essential factors and these are the condition of the wheel-rail contact and the vehicle velocity [3].

The loss of adhesion between the wheel and rail has serious influences on the traction and braking effort of the vehicle. Lately, various approaches have been proposed to outline the reasons for the loss of adhesion [4-7]. These

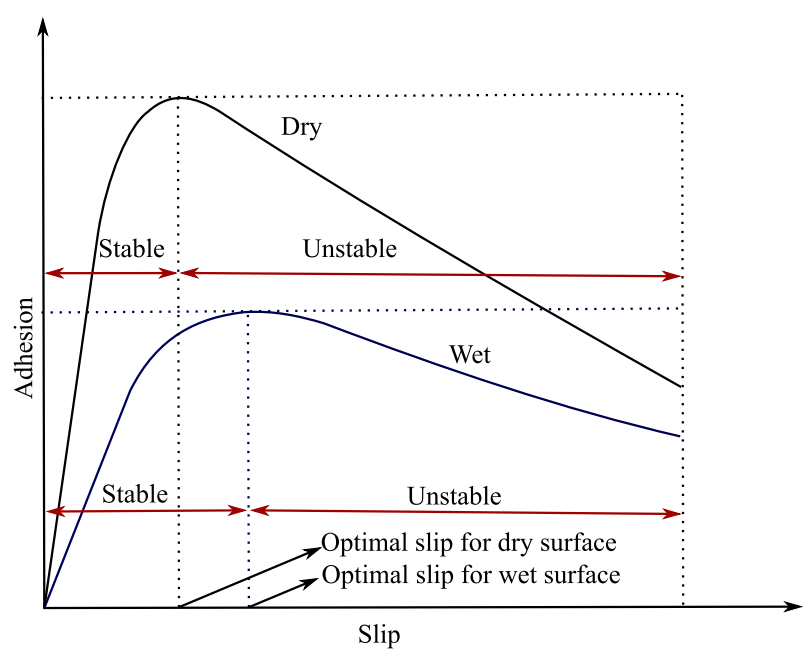

Fig. 1 Slip-adhesion curve illustrating the characteristic of coefficient of adhesion (CoA) under dry and wet contact conditions [3] 
studies show that the loss of adhesion may occur due to the presence of the water in several forms (rain, snow, dew etc.), grease and leaf contaminants. In other words, this loss of adhesion is mainly due to the presence of the third body between wheel and rail. Besides, it is essential to model this loss of adhesion accurately. The presence of the friction force also cause a cleaning effect on the contact area where adhesion recovery occurs due to the removal of the third body particles. This behaviour is highly nonlinear and complex. Polach [8] provided a tangential force model for such conditions and this model is frequently considered. Recently, more accurate and efficient models are proposed for degraded adhesion conditions and adhesion recovery [9-12]. Nevertheless, it has been shown in [13] experimentally that the model proposed in [8] is adequate and sufficient for a wheel slide protection controller. The model proposed in [8] is also considered in this study.

It is known that the poor adhesion condition causes wheel slip during the traction process and wheel skid during the braking process. The lifetime wear of the wheel and overall traction performance of a railway vehicle are greatly influenced by the excessive slip and skid [14]. Therefore, utilization of the maximum adhesion is critical by considering re-adhesion control methods. A considerable amount of literature has been published on wheel slip control [15-24]. Ryoo et al. [15] proposed a method based on the conventional pattern and speed difference control to use a maximum adhesive effort and to improve traction performance. When the actual value of the wheel slip exceeds a certain threshold value, the torque of the traction motor is lowered to prevent the wheel slip. However, it is observed from the presented results that the controller does not provide the maximum possible adhesion. A wheel slip control method without using the speed sensor for the electric railway vehicle for multiple-induction motor drive type was proposed by Yamashita and Watanabe [16]. The advantages of this method are that it reduces the cost of the controller, the probability of failure and the complexity of the controller. However, the control system may suffer from frequent wheel slip oscillations and excessive torque drop compared to the conventional method. Mei et al. proposed a method based on torsional analysis of traction system [25]. The proposed method investigates the variation in wheel slip dynamic properties due to the condition change at the wheel-rail contact. The results are used to detect and control the wheel slip. However, this method is not a reliable enough for rail vehicle applications [26]. Acceleration based slip regulation method proposed by Yamashita and Soeda [17] is another alternative wheel slip control methodology. The method does not require the longitudinal velocity of the vehicle for the control process. Even though the method has an effective wheel slip control performance, optimum utilization of the adhesion is not realized. Zirek et al. [20] has proposed an adaptive sliding control scheme. The controller design process considers system uncertainties and disturbances. The presented results reveal that the response of the proposed control algorithm is rather satisfactory in the stabilization of wheel slip and improvement of traction ability. However, accurate measurement of the adhesion force is required.

Spiryagin et al. [27] highlighted that it is useful to consider adhesion estimation approaches for anti-slip control. The majority of these approaches are model-based [28] and they considered inverse dynamic modelling [29, 30], family of Kalman filters [31-34], artificial neural network [35] and swarm intelligence-based method $[36,37]$.

The information about the friction condition of the wheel and rail is essential for realization of the optimum utilization of adhesion. Such a re-adhesion controller based on friction estimation is proposed in [33] and for friction estimation an extended Kalman filter is considered. However, estimation approach in [33] requires measurements of voltages, currents and angular velocity of the electrical motor. Recently, a swarm intelligence-based multiple model methodology has been proposed [36-39] and this methodology only requires the measurement of the angular velocity of a wheel and the translational velocity of the vehicle, thus, voltage or current measurements are not needed. In fact, this approach is a multiple models approach and it is based on manipulating the particle swarm optimization to work with noisy measurements. Therefore, it is different from the conventional particle swarm optimization which is frequently used in the railway domain [40].

In order to overcome the disadvantages of the aforementioned control methodologies, the conventional proportional-integral (PI) controller can be employed to control the wheel slip and increase the traction performance of vehicle. However, the main disadvantage of the conventional PI controller is that the optimum slip-ratio changes when alteration occurs in adhesion condition. Therefore, in this paper, a PI wheel slip control method based on simultaneous adhesion estimation with swarm intelligence [36, 37] is proposed to control the wheel slip and improve the traction performance. To validate the performance of the controller, the mathematical model of an experimental test stand and measurements from this roller-rig are considered. The performance of the proposed control strategy is verified for several wheel-roller surface conditions (dry, water and greasy). The results show that the PI wheel slip control method with swarm intelligencebased adhesion estimation can prevent wheel slip more effectively than the conventional method and improve the traction performance. 


\section{General structure of the methodology}

The adhesion estimation process considered in this study is based on multiple mathematical models of the system. In general case, this mathematical model can be a dynamic model of a railway vehicle with traction. In order to verify results, a tram wheel test stand, which simulates the traction system of some trams with independently rotating wheels in Czechia, is considered. This test stand is a full scale, wheel on roller type roller-rig, and it was previously used for validation purpose many times $[9,20,36-38,41-44]$.

The application of the approach for railway vehicles is summarized in Fig. 2. The system is initialized by considering the proper initial conditions and models in these figures represent the mathematical representations of the traction system of a vehicle (tram wheel test stand in this case). In order to estimate adhesion condition, creepage (or slip) output of each model is compared with the measurements taken from the system. Adhesion information of each model evolves with respect to the method presented in [36-38]. Then, a reference creepage for adhesion optimum is determined by considering the adhesion estimation and the error between reference creepage and actual creepage is fed to the slip controller to generate control torque.
Additionally, realization of the methodology on the tram wheel test stand in this study is illustrated in Fig. 3. In following sections, details of each model and subsystem are presented.

\section{Experimental set-up and mathematical models}

Figures 4 and 5 show a schematic drawing and appearance of the full-scale tram wheel test stand that is located at the Educational and Research Centre in Transport of the University of Pardubice. The test stand is equipped with a $58 \mathrm{~kW}$ torque controlled permanent magnet synchronous motor (PMSM) and a $55 \mathrm{~kW}$ scalar controlled asynchronous motor (AM). PMSM controls a tram wheel in diameter of $696.40 \mathrm{~mm}$ and $\mathrm{AM}$ controls a roller (rotating rail) in diameters of $900.44 \mathrm{~mm}$. The traction is provided by PMSM motor while AM provides opposing torque to keep the wheel at the constant speed $[9,45]$. Both rotating parts are placed on a main frame in vertical direction. The roller is placed on a base plate that provides setting of the angle of attack. On the other hand, the wheel is mounted on a swinging arm which enables the wheel to move in vertical axis. The swinging arm aims to press the wheel towards the roller with the help of an air spring [45].

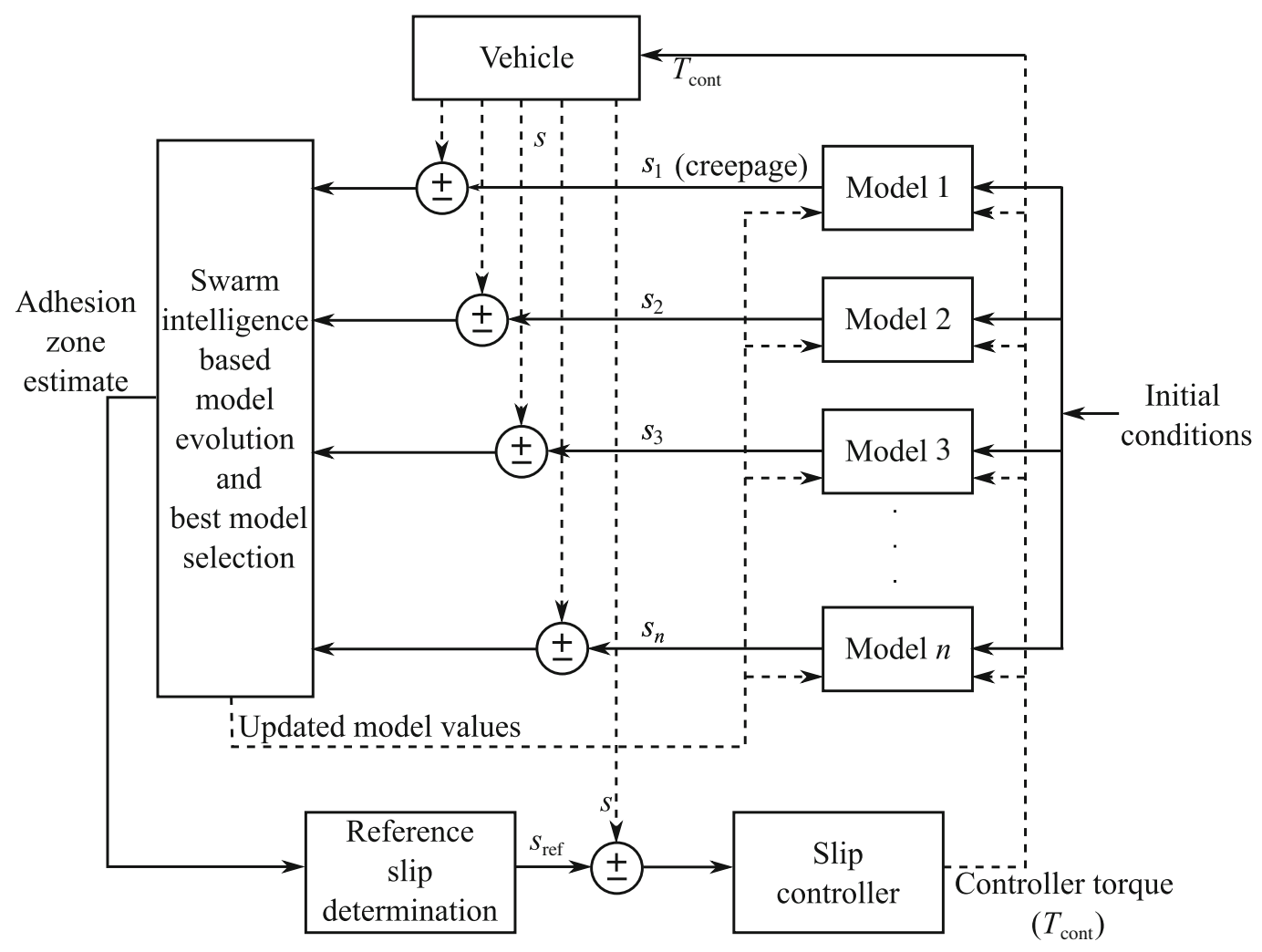

Fig. 2 General structure of the methodology with adhesion estimation approach 


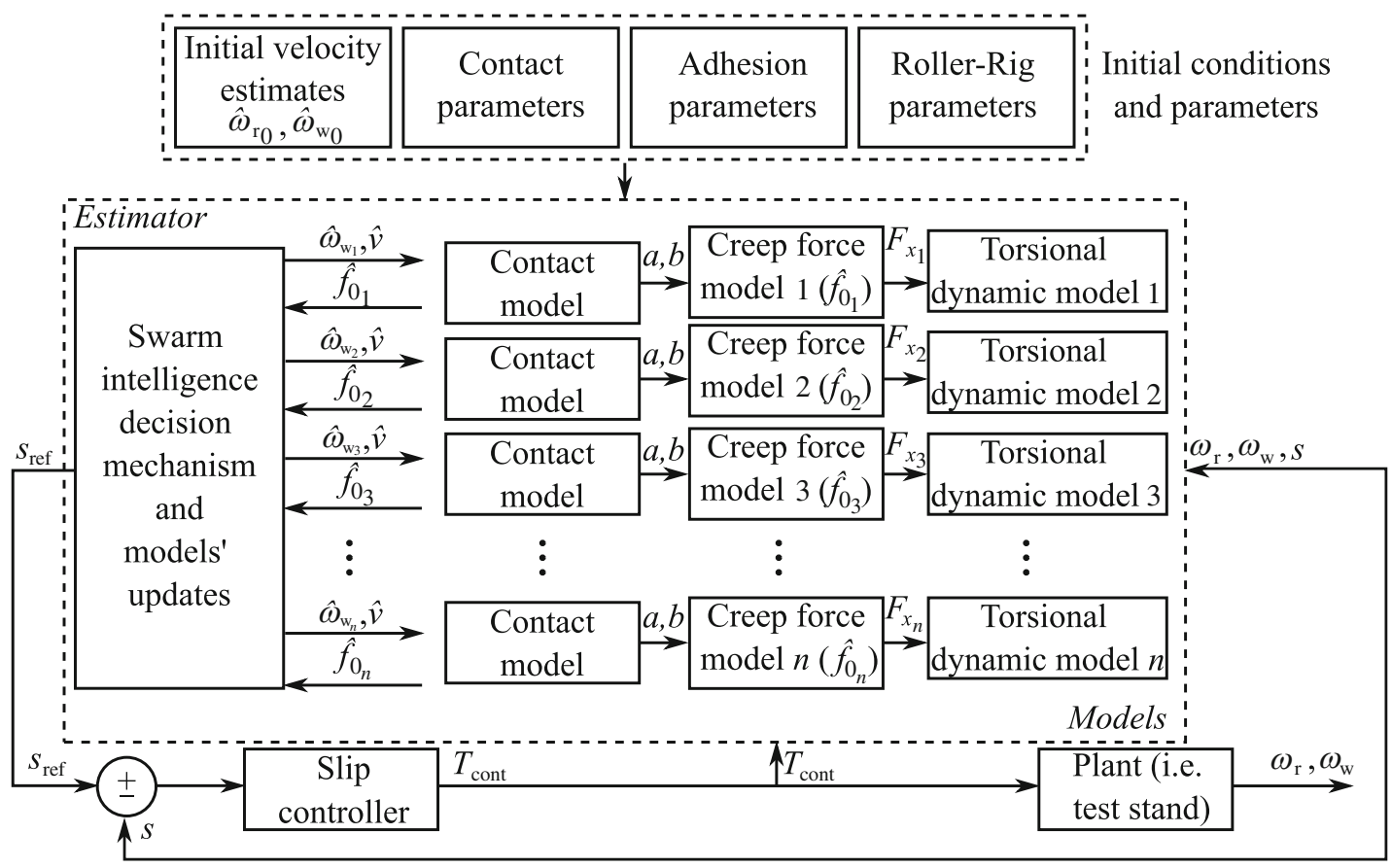

Fig. 3 Realization of the methodology on the tram wheel test stand

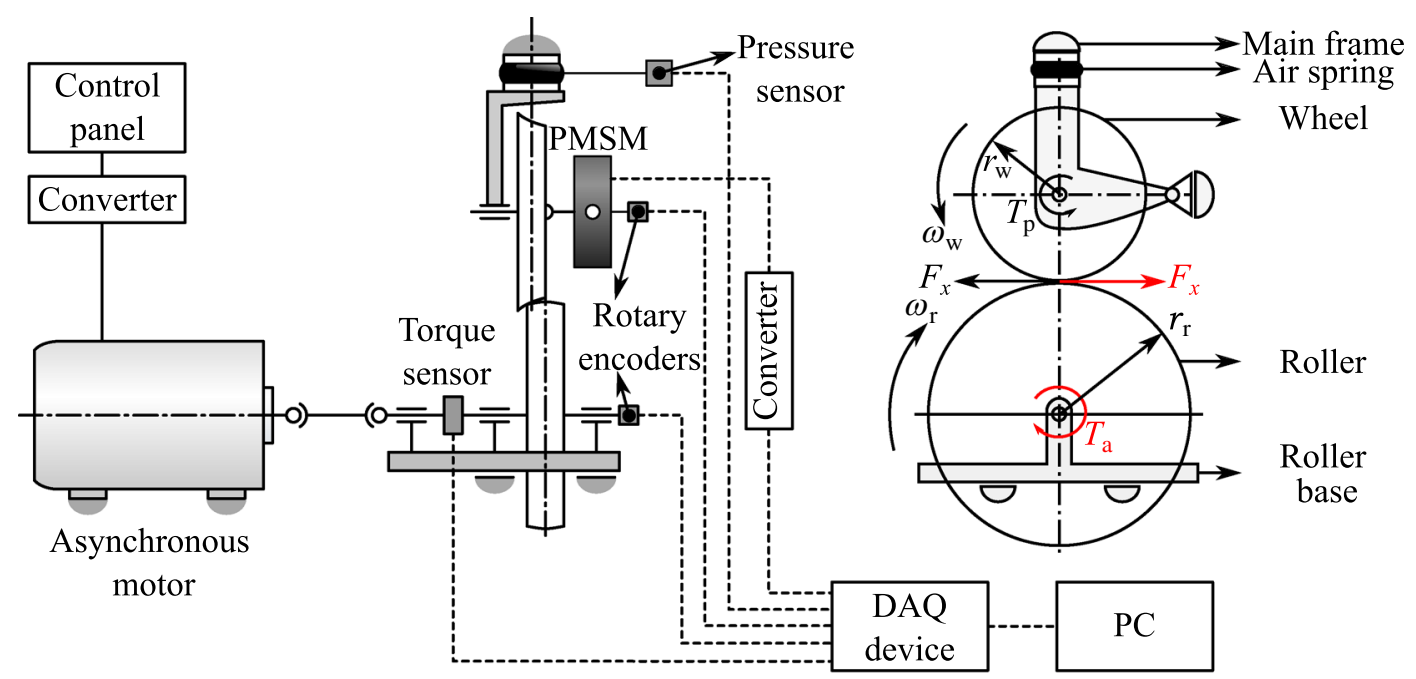

Fig. 4 Schematic drawing of the test stand [43]

Incremental rotation sensors (type IRC315) installed on the drive shafts measure the angular speeds of the wheel and roller. Similarly, a strain gauge torque transducer placed on the roller drive shaft monitors the adhesion force between the wheel and roller. A pressure transmitter (type DMP331) is used to measure the pressure applied by the pneumatic air spring. The measurements gathered from the torque transducer and pressure transmitter are used to calculate the coefficient of adhesion [9].
All measurements from the test stand are recorded with $200 \mathrm{~Hz}$ sampling frequency on a data acquisition device (DAQ-type NI USB-6341). However, the action of the wheel slip controller is limited with $25 \mathrm{~Hz}$ frequency [45].

Measurements contain periodic and parasitic signals and the main sources of these signals are the imperfection of the test stand and out-of-roundness of the wheel and roller. Since the frequency of the parasitic signals is equal to the rotation frequency of the roller, they can be easily filtered using an appropriate filtering method [9]. 

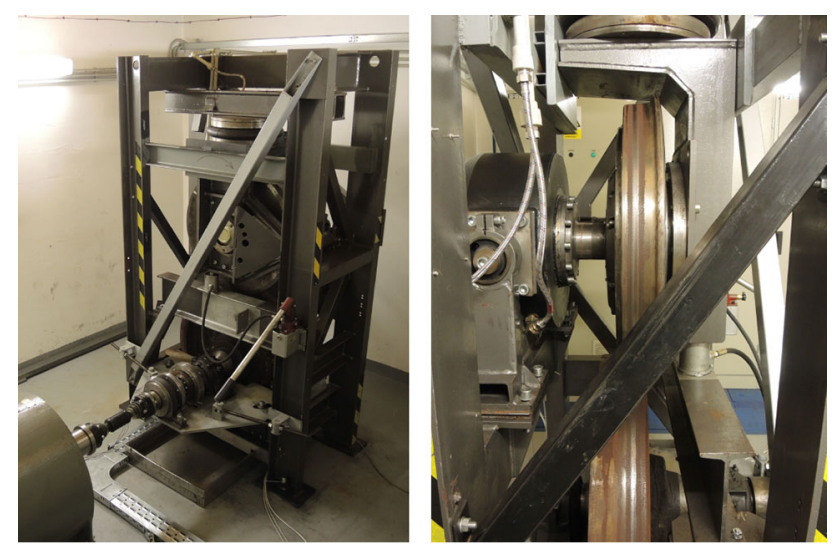

Fig. 5 Photos of the test stand

\subsection{Simulation model of the tram wheel test stand}

A mathematical model of the above-mentioned experimental tram wheel test stand is created to evaluate the performance of the PI wheel slip control method along with the swarm intelligence-based adhesion estimation. Dynamic model of the PMSM, Thevenin equivalent model of AM, Polach adhesion force model, PI controller and swarm particle friction estimator are the main components of the test stand and they are considered in the mathematical model. To solve the differential equations, a fourthorder Runge-Kutta method is considered with $20 \mu$ s time step to guarantee the accuracy of calculations. On the other hand, the reaction of the controller is limited to $0.04 \mathrm{~ms}$ to simulate the response of experimental test stand. The structure of the developed mathematical model is summarized in Fig. 6.

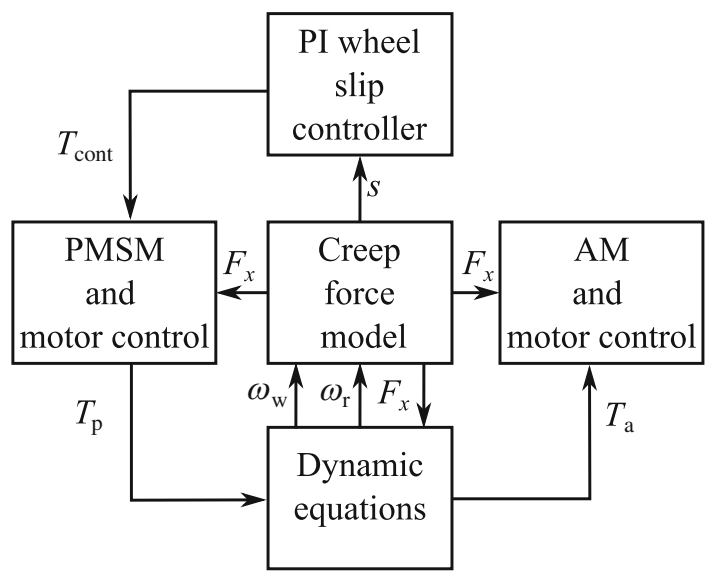

Fig. 6 Structure of the developed mathematical model of the tram wheel test stand

\subsubsection{Dynamic model of the tram wheel test stand}

A free body diagram of the test stand to derive dynamic model of the tram wheel test stand is provided in Fig. 4. The effect of drive shaft and connection elements for wheel/roller and motors (PMSM/AM) is neglected. In addition, neglecting the lateral, yaw and pitch rolling resistance dynamics are among the model assumptions. The equation of the motion for the wheel and roller is provided in (1) [20].

$$
\begin{aligned}
& \dot{\omega_{\mathrm{r}}}=\frac{-T_{\mathrm{a}}-F_{x} r_{\mathrm{r}}}{J_{\mathrm{r}}}, \\
& \dot{\omega}_{\mathrm{w}}=\frac{T_{\mathrm{p}}+F_{x} r_{\mathrm{w}}}{J_{\mathrm{w}}} .
\end{aligned}
$$

\subsubsection{Dynamic model of PMSM}

The test stand has a special PMSM that is developed for low floor trams. PMSM has $58 \mathrm{~kW}$ nominal power, $852 \mathrm{Nm}$ nominal torque, $650 \mathrm{rpm}$ nominal speed and 122 A nominal phase current [46]. PMSM is excited by permanent magnets. Simplification of the dynamic equations are due to the absence of the flux and dumping windings as shown in (2) [47]:

$$
\begin{aligned}
\frac{\mathrm{d} i_{d}}{\mathrm{~d} t} & =\frac{1}{L_{d}} V_{d}-\frac{R_{\mathrm{s}}}{L_{d}} i_{d}+\frac{L_{q}}{L_{d}} \omega_{\mathrm{e}} i_{q}, \\
\frac{\mathrm{d} i_{q}}{\mathrm{~d} t} & =\frac{1}{L_{q}} V_{q}-\frac{R_{\mathrm{s}}}{L_{q}} i_{q}-\frac{L_{d}}{L_{q}} \omega_{\mathrm{e}} i_{d}-\frac{\varphi}{L_{q}} \omega_{\mathrm{e}}, \\
T_{\mathrm{p}} & =\frac{3}{2} p\left[\varphi i_{q}-\left(L_{d}-L_{q}\right) i_{q} i_{d}\right],
\end{aligned}
$$

where $V_{d}$ and $V_{q}$ are $d$ - and $q$-axis components of stator phase voltage, $i_{d}$ and $i_{q}$ are $d$ - and $q$-axis components of stator current, $R_{\mathrm{S}}$ is the resistance of the stator windings, $\varphi$ is the flux induced by the permanent magnet of the rotor, $L_{d}$ and $L_{q}$ are $d$ - and $q$-axis stator self-inductances, $\omega_{\mathrm{e}}$ is the electrical speed of the rotor, $T_{\mathrm{p}}$ is electromagnetic torque and $p$ is the number of pole pairs. The electrical speed and angular position of rotor are determined using (3):

$$
\begin{aligned}
\frac{\mathrm{d} \omega_{\mathrm{e}}}{\mathrm{d} t} & =\frac{p}{J_{\mathrm{w}}}\left(T_{\mathrm{p}}-F_{x} r_{\mathrm{w}}\right), \\
\frac{\mathrm{d} \theta_{\mathrm{e}}}{\mathrm{d} t} & =\omega_{\mathrm{e}},
\end{aligned}
$$

where $\theta_{\mathrm{e}}$ is the position of the rotor.

It is possible to reach best utilization of the current and high efficiency of drive if flux current component $\left(i_{d}\right)$ is set to zero. This means that the current space vector is perpendicular to the flux [47]. Then (2c) can be simplified and re-written in order to determine the reference torque current component as given in (4), 
$i_{q}^{*}=\frac{T_{\mathrm{p}}^{*}}{1.5 p \varphi}$

where $T_{\mathrm{p}}^{*}$ is reference control torque and $i_{q}^{*}$ is reference torque current component. The electrical parameters of the PMSM are provided in Table 1.

Hysteresis current control strategy is employed to control the PMSM. The hysteresis current control is a PWM technique. The actual current signal is compared with the reference current signal. The states of the inverters change in case the actual current exceeds the reference current in a certain range so that the actual current follows the reference current [48]. The control structure of the PMSM is illustrated in Fig. 7. Simanek et al. [47, 49] presented detailed information about PMSM and its drive system.

\subsubsection{Dynamic model of asynchronous motor}

An asynchronous motor drives the roller to generate a braking torque against the driving torque of the wheel. In other words, AM aims to keep the system at a constant speed. Furthermore, AM is used to simulate different running speeds of the rail vehicle [50]. The experimental

Table 1 Electrical parameters of PMSM

\begin{tabular}{ll}
\hline Parameter & Value \\
\hline$R_{\mathrm{S}}$ & $0.087 \Omega$ \\
$L_{d}$ & $0.8 \mathrm{mH}$ \\
$L_{q}$ & $0.8 \mathrm{mH}$ \\
$\varphi$ & $0.212 \mathrm{~Wb}$ \\
$J_{\mathrm{w}}$ & $0.95 \mathrm{~kg} \cdot \mathrm{m}^{2}$ \\
$p$ & 22 \\
\hline
\end{tabular}

AM has $55 \mathrm{~kW}$ nominal power, $891 \mathrm{Nm}$ nominal torque, 133 A rated current, $3 \times 380 \mathrm{~V}$ rated voltage and $50 \mathrm{~Hz}$ rated frequency [49]. The Thevenin equivalent model of AM is provided in Fig. 8. Braking torque produced by the AM can be calculated as by using provided Thevenin equivalent model in (5):

$$
T_{\mathrm{a}}=\frac{3}{\omega_{\mathrm{syn}}} \frac{V_{\mathrm{Th}}^{2}}{\left(R_{\mathrm{Th}}+\frac{R_{2}^{\prime}}{s_{\mathrm{a}}}\right)^{2}+\left(X_{\mathrm{Th}}+X_{2}^{\prime}\right)^{2}} \frac{R_{2}^{\prime}}{s_{\mathrm{a}}} .
$$

The electrical parameters for the Thevenin equivalent circuit of AM are provided Table 2.

\subsubsection{Wheel-roller contact model}

The adhesion force between wheel and roller is calculated using the method of Polach [8]. The method considers the effect of vehicle speed, longitudinal slip and shape of the contact ellipse. It has the advantage over more detailed contact theories by allowing shorter computation time while not diverging significantly from the exact theory even pure longitudinal and steady rolling are considered.

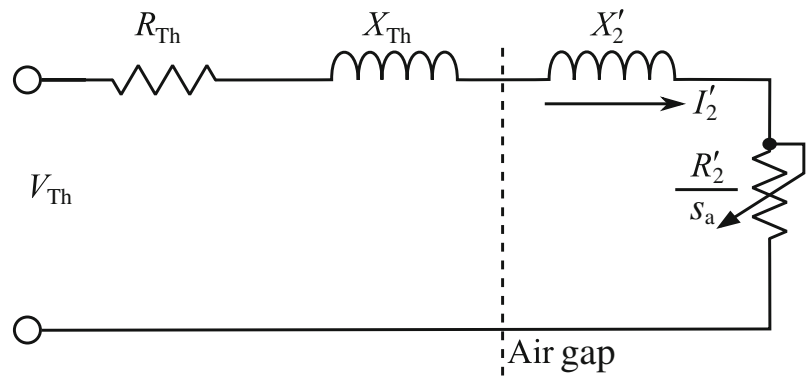

Fig. 8 The Thevenin equivalent model of AM [20]

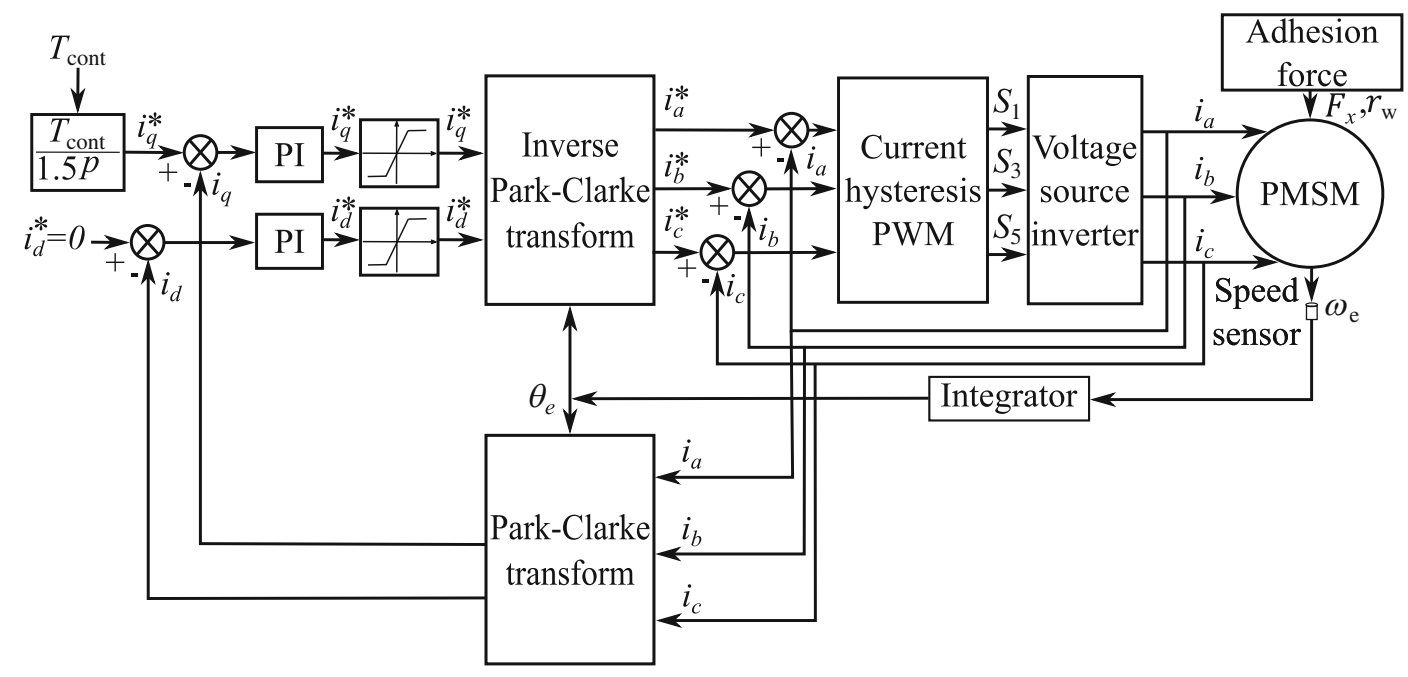

Fig. 7 Control structure of the PMSM [20] 
Table 2 Electrical parameters for the Thevenin equivalent circuit of AM

\begin{tabular}{ll}
\hline Parameter & Value $(\Omega)$ \\
\hline$R_{\mathrm{Th}}$ & 0.0226 \\
$R_{2}^{\prime}$ & 0.0181 \\
$X_{\mathrm{Th}}$ & 0.2007 \\
$X_{2}^{\prime}$ & 0.3010 \\
\hline
\end{tabular}

Table 3 Polach creep force model parameters according to the surface contamination

\begin{tabular}{lllll}
\hline & $f_{0}$ & $A$ & $B$ & $k_{\text {red }}$ \\
\hline Dry & 0.437 & 0.5 & 0.5 & 0.4 \\
Water & 0.287 & 0.2 & 0.1 & 0.4 \\
Greasy & 0.075 & 0.2 & 0.1 & 0.05 \\
\hline
\end{tabular}

The method uses the variable coefficient of friction in (6a) and scaled slip in (6b) to calculate the coefficient of adhesion $(\mathrm{CoA})$ as given in $(6 \mathrm{c})$.

$f=\left|f_{0}\left[(1-A) \mathrm{e}^{-B|w|}+A\right]\right|$,

$\varepsilon=\frac{a K|s|}{p_{\max } f} k_{\mathrm{red}}$,

$\mu=\frac{2}{\pi} f\left(\arctan (\varepsilon)+\frac{\varepsilon}{1+\varepsilon^{2}}\right)$.

The parameter sets of Polach's method for various surface conditions are given in Table 3. The provided parameter sets are gathered from the experimental measurements and mathematical model of the test stand.

\section{PI wheel slip controller}

Proportional-integral-derivative (i.e. PID) controllers are based on a feedback control loop which calculates an error signal by taking the difference between the output of a system and the desired set point. In most of the process industries, PI and PID are generally used due to their simple design and tuning methods. However, the PI controllers are more preferable than the PID controllers because of being less sensitive to the noise and more simple [51]. Since the measurements from the tram wheel test stand have noise both due to the electrical and mechanical subsystems, the PI controller is chosen for the wheel slip control.

The PI controller can be used for the railway vehicles to control wheel slip and improve their traction performance. For an effective control, a reference slip value that is close to the peak of the slip-adhesion curve can be chosen to be used as a control signal. It is also important that the selected reference slip value is on the stable side of the slip-adhesion curve. However, determination of such reference is not easy task since the adhesion condition differs due to the contamination between wheel and rail.

The discrete time form of the control torque produced by PI controller is expressed as

$$
T_{\text {cont }}(k)=T_{\text {cont }}(k-1)+K_{\mathrm{p}}(e(k)-e(k-1))+K_{\mathrm{i}} e(k),
$$

where $T_{\text {cont }}$ is the output torque of the controller, $K_{\mathrm{p}}$ is the proportional gain of the controller, $K_{\mathrm{i}}$ is the integral gain of the controller, $k$ is the iterative step, $e$ is the error between the actual slip and desired slip. The error is calculated as

$e(k)=s_{\text {ref }}(k)-s_{\text {act }}(k)$,

where $s_{\text {ref }}$ is the reference wheel slip value, and $s_{\text {act }}$ is the actual wheel slip value.

The functionality of the control parameters of PI $\left(K_{\mathrm{p}}\right.$ and $K_{\mathrm{i}}$ ) controller can be summarized as [52]

- $K_{\mathrm{p}}$ provides an overall control action proportional to the error signal through the all-pass gain factor.

- $K_{\mathrm{i}}$ reduces the steady-state error through low-frequency compensation by an integrator.

The effects of increasing PI control parameters on the system are presented in Table 4.

A block diagram of the PI slip controller is provided in Fig. 9. The difference between the desired slip and actual slip (error) is calculated and sent to the PI torque regulator as an input signal. The PI torque controller regulates the torque applied to wheel with respect to error signal. The torque limiter is used to prevent the generated torque to exceed maximum torque of the synchronous motor. The comparator is utilized to make the decision between the driver torque request and regulated torque.

The reference wheel slip is determined according to the swarm intelligence-based adhesion zone estimation, and the reference values with respect to the predetermined zones are provided in Table 5 .

\section{Swarm intelligence-based multiple models for adhesion estimation}

Particle swarm optimization is a nature inspired method to optimize nonlinear systems based on the movement of bird flocks [53]. In [36, 37], the idea behind this optimization method is arranged for multiple model-based maximum friction coefficient $\left(f_{0}\right)$ estimation.

As stated in [37], in order not to increase computational complexity, minimum number of models are determined as 
Table 4 Effect of increasing PI control parameters to the system

\begin{tabular}{|c|c|c|c|c|c|}
\hline & Rise time & Overshoot & Settling time & Steady state error & Stability \\
\hline$K_{\mathrm{p}}$ & Decrease & Increase & Small increase & Decrease & Degrade \\
\hline$K_{\mathrm{i}}$ & Decrease & Increase & Increase & Large decrease & Degrade \\
\hline
\end{tabular}

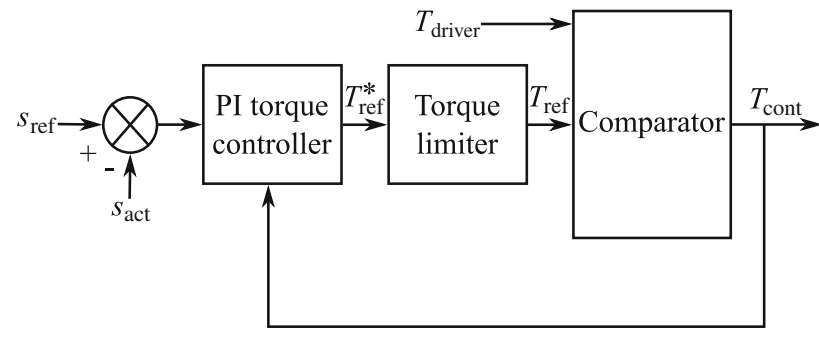

Fig. 9 Block diagram for PI slip controller

Table 5 Reference slip determination

\begin{tabular}{ll}
\hline Static friction estimation $\left(\hat{f_{0}}\right)$ & $s_{\text {ref }}$ \\
\hline $0.02 \leq \hat{f_{0}}<0.15$ & 0.0228 \\
$0.15 \leq \hat{f_{0}}<0.30$ & 0.0202 \\
$0.30 \leq \hat{f_{0}}<0.70$ & 0.0180 \\
\hline
\end{tabular}

five and this number of models also considered in this study. The static friction coefficient estimate is distributed uniformly between models. Considering the adhesion limits determined from the operation of a railway vehicle, parameter estimate set is initially chosen as $\hat{f_{0}}=[0.02,0.19,0.36,0,53,0.70]$. The limits for the static friction is obvious from the Table 5 , and it is expressed as

$0.02 \leq f_{0} \leq 0.70$.

Since the static (i.e. maximum) friction coefficient is the dominant parameter for the adhesion and creep force model, only it is estimated and other parameters are assumed to be constant and they are given in Table 3. There are three different adhesion zones presented in Table 5 , namely low adhesion zone $\left(0.02 \leq \hat{f_{0}}<0.15\right)$, wet zone $\left(0.15 \leq \hat{f_{0}}<0.30\right)$ and dry zone $\left(0.30 \leq \hat{f_{0}}<0.70\right)$. Other parameters, which are used in the calculation of creep force and adhesion, considered with respect to the static friction coefficient estimate. If static friction coefficient estimate falls into low adhesion zone $\left(0.02 \leq \hat{f_{0}}<0.15\right)$ for example, then $A, B$ and $k_{\text {red }}$ are taken with respect to the values given in Table 3 for greasy contact condition. Selection of the best model is straightforward and expressed as the model with minimum cost function. It is given as

$J=\left|s_{i}-s_{\text {act }}\right|, \quad i=1,2, \ldots, n$,

where $J$ is the cost function, $n$ is the number of models ( $n=5$ in this study) and $i$ represents the model index. The evolution of the models is determined based on the velocity of each particle, and it is expressed as

$$
V_{i}=\omega \times V_{i}+c \times r \times\left(\hat{f_{0_{\text {best }}}}-\hat{f_{0_{i}}}\right), \quad i=1,2, \ldots, n
$$

where $V_{i}$ is the velocity of each particle, $\hat{f}_{0_{\text {best }}}$ is the best estimate from previous time step, $\hat{f_{0_{i}}}$ is the current estimate for the corresponding parameter, $\omega$ is the inertia weight, $c$ is the acceleration coefficient (considered as 2 here), and $r$ is a random number between zero and one.

The difference between the conventional particle swarm optimization technique and the method presented here is the exclusion of the global best particle in (11). This is mainly due to the noise exists in measurements. In order to decrease the effect of noise, it is useful to eliminate the historical information (i.e. the global best model) [54]. Therefore, the global best model is omitted in this study.

According to the [55], a linearly decreasing inertia weight provides the minimum error criterion, it is also considered in this study and expressed as

$\omega=\omega_{\max }-\frac{\omega_{\max }-\omega_{\min }}{N_{\mathrm{i}}} k$,

where $\omega_{\min }$ and $\omega_{\max }$ are selected as 0.4 and 0.9 , respectively, $N_{\mathrm{i}}=1000$ is the maximum iteration number, and $k$ is the iteration index. Lastly, parameter estimates of the models are updated as

$\hat{f_{0_{i}}}=\hat{f_{0_{i}}}+V_{i}$.

Velocities in conventional particle swarm optimization method may explode to larger values quickly. Shahzad et al. [56] proposed a velocity clamping method to overcome such an issue. It is given as

$V=\left\{\begin{array}{lll}V_{\max } & \text { if } \quad V_{\max }<V, \quad V_{\max }=0.02, \\ V_{\min } & \text { if } \quad V<V_{\min }, \quad V_{\min }=-0.02 .\end{array}\right.$

Furthermore, in order to enhance the exploration capability of the models a velocity based re-initialization [57] is applied in this study. If the mean absolute value of the 


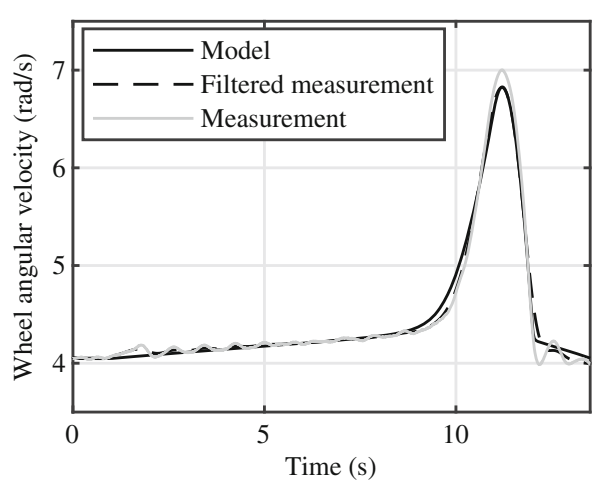

(a) Wheel rotational speed

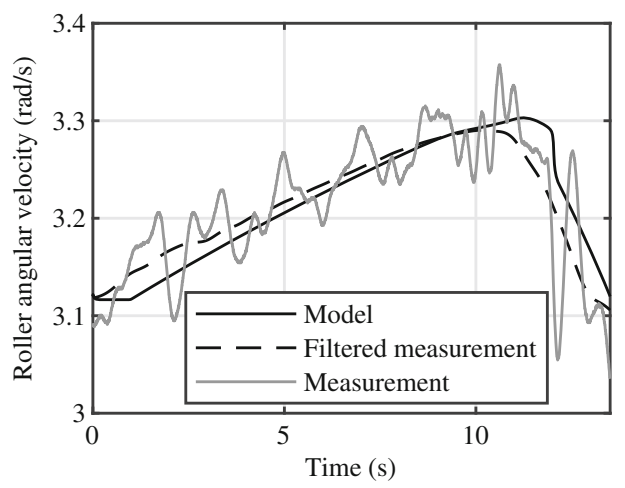

(b) Roller rotational speed

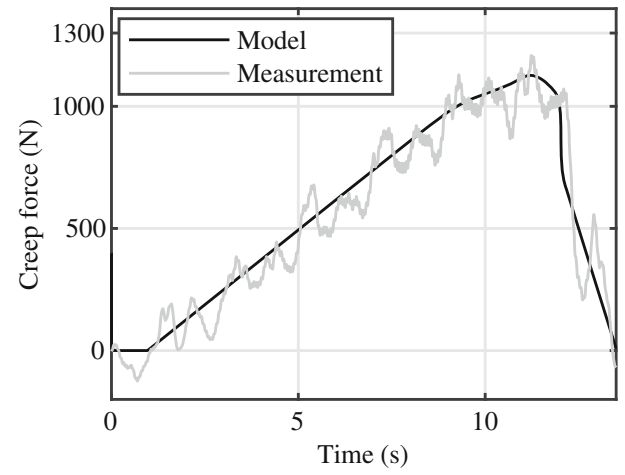

(c) Creep force

Fig. 10 Validation of the model for wet condition at $5 \mathrm{~km} / \mathrm{h}$ speed

velocities of the model is smaller than a threshold value (it is $10^{-4}$ here), the parameter set of the models is initialized to $\hat{f_{0}}=[0.02,0.19,0.36,0,53,0.70]$. Thus, exploration capability of the method is improved.

The performance of the swarm intelligence-based adhesion estimation considered here is discussed in [37] for which the same method applied in same experimental conditions. In case of five models, it has shown in [37] that elapsed time for all simulation and experiment duration approximately corresponds to each other. Therefore, this method is suitable to be used in practice. Ref. [37] provides further details.

\section{Model validation, results and discussion}

\subsection{Validation of the model}

In this study, measurements taken from the test stand are considered, and the use of test rigs is a common validation strategy for such applications [20, 21, 33, 44, 58]. This model has been validated several times in previous studies [36, 37, 39, 41, 43, 59]. Two cases are given hereby to show that the constructed model represents the physical system. The first measurements are taken for wet conditions at $5 \mathrm{~km} / \mathrm{h}$ translational speed, and the second one is obtained for greasy conditions at $20 \mathrm{~km} / \mathrm{h}$. The results for the first case are provided in Fig. 10. Noise on the measurements is also shown. Noise is especially apparent for the roller speed. The sources of this noise is mentioned in Sect. 3. In order to filter out this noise, a moving average filter is considered based on the translational speed since the period of this noise depends on the speed. This dependency is revealed in Fig. 12 where the model is validated for greasy conditions at $20 \mathrm{~km} / \mathrm{h}$ speed.

It is evident from Fig. 11 that there are three phases, and these are constant speed, acceleration and deceleration of the wheel due to the PMSM torque request. Torque requests from PMSM are provided in Figs. 11 and 13.

In order to show the effectiveness of the proposed scheme, another simulation case including an adhesion condition change at $20 \mathrm{~km} / \mathrm{h}$ speed is provided. In this case, the torque request from PMSM is given in Fig. 14. It is assumed that at $30 \mathrm{~s}$, maximum friction coefficient drops from 0.437 to 0.2 . Gaussian noise is added to the speed results of the model in this case, and measurements are generated. When controller is applied for this case, these generated measurements from the model are considered. 


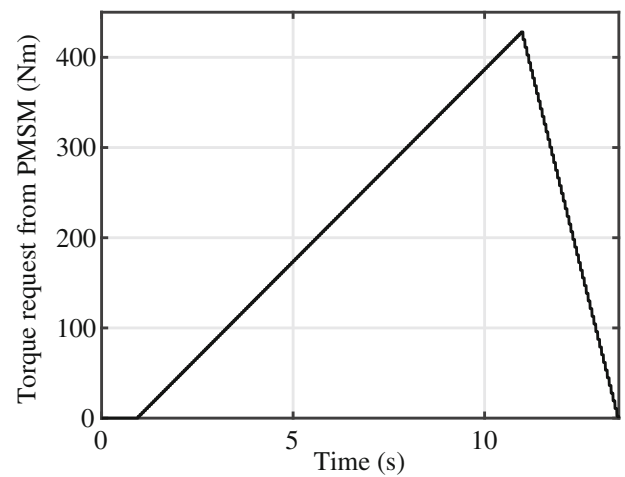

(a) PMSM torque profile

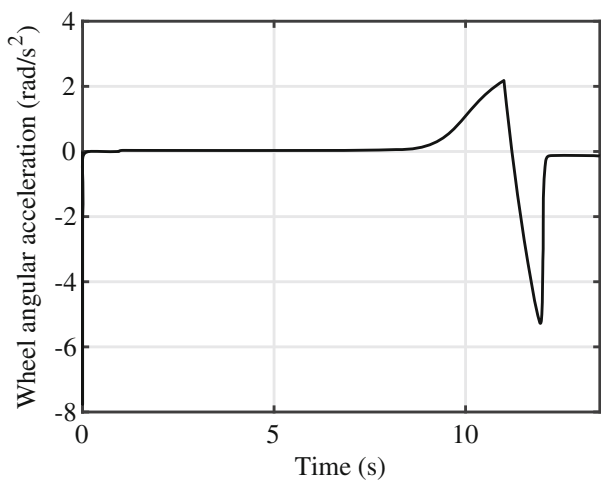

(b) Wheel angular acceleration

Fig. 11 Torque request from PMSM and wheel angular acceleration obtained from model for wet condition at $5 \mathrm{~km} / \mathrm{h}$ speed

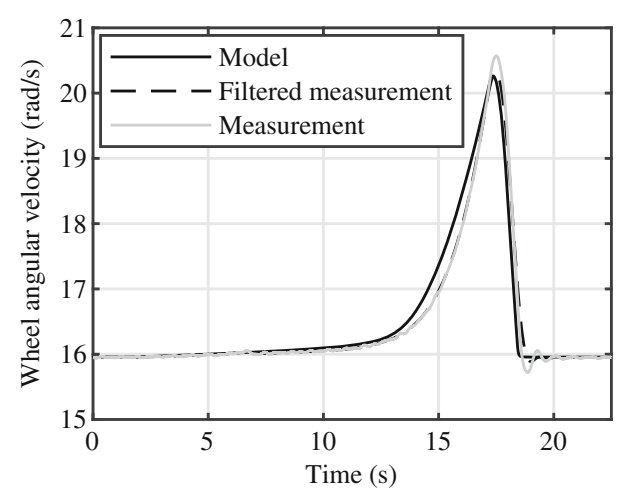

(a) Wheel rotational speed

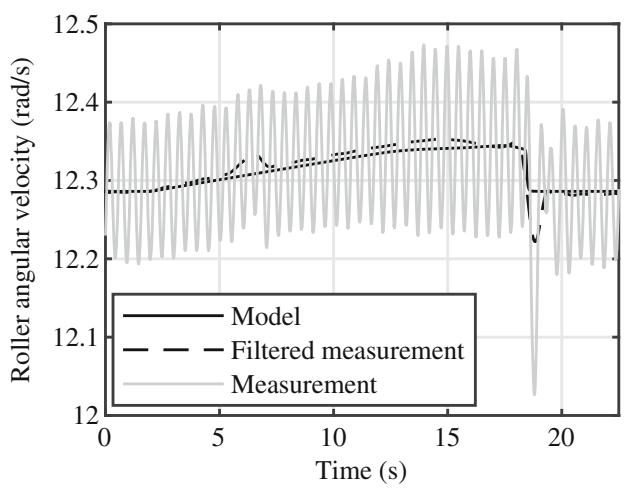

(b) Roller rotational speed

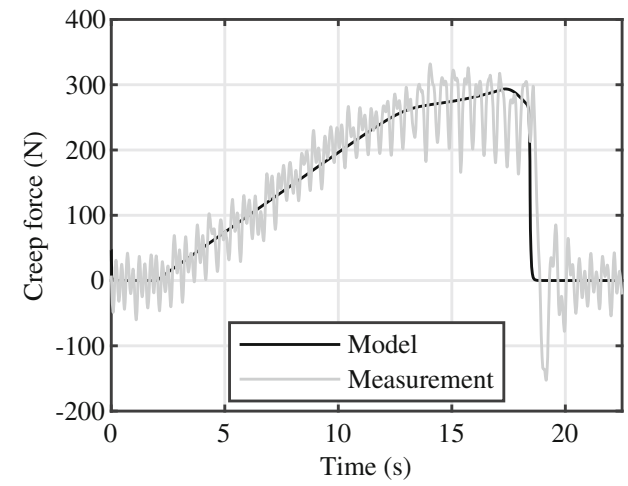

(c) Creep force

Fig. 12 Validation of the model for greasy condition at $20 \mathrm{~km} / \mathrm{h}$ speed

\section{Results and discussion}

The performance of the PI controller with swarm intelligence-based adhesion estimation is verified using the mathematical model of the tram wheel test stand and measurements that is mentioned in previous sections. This model is developed to match the measurements from the experimental test stand and with regard to nonlinear effects resulted by time delay and disturbances. The simulation strategy is intended to simulate dry, wet and greasy wheelroller surface conditions. For the investigation, two speeds of $5 \mathrm{~km} / \mathrm{h}$ and $20 \mathrm{~km} / \mathrm{h}$ are selected to simulate the 


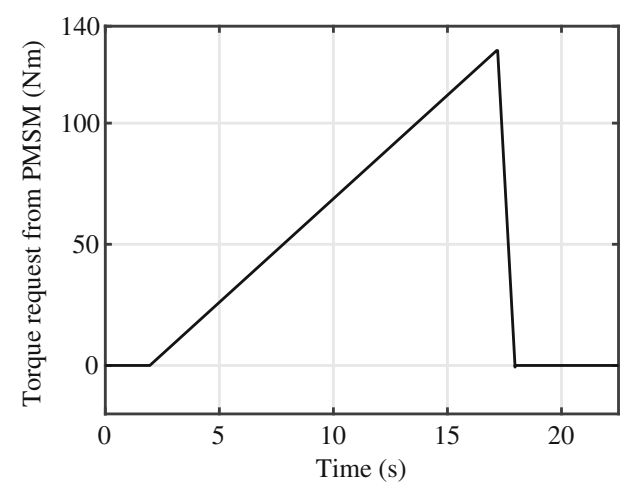

(a) PMSM torque profile

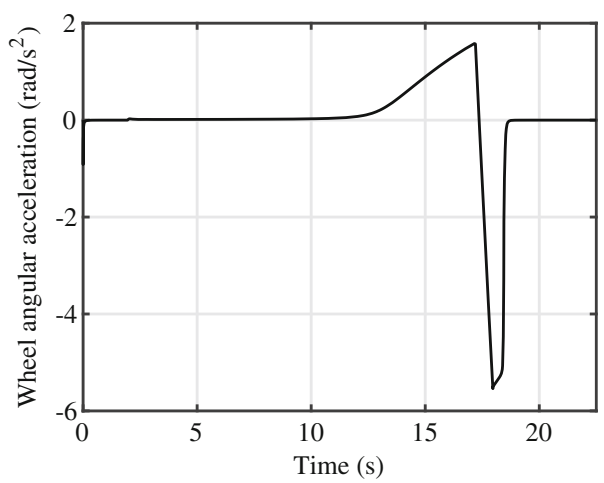

(b) Wheel angular acceleration

Fig. 13 Torque request from PMSM and wheel angular acceleration obtained from the model for greasy condition at $20 \mathrm{~km} / \mathrm{h}$ speed

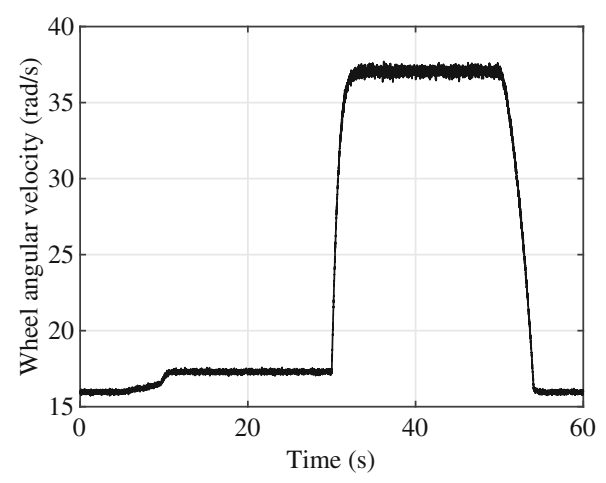

(a) Wheel rotational speed

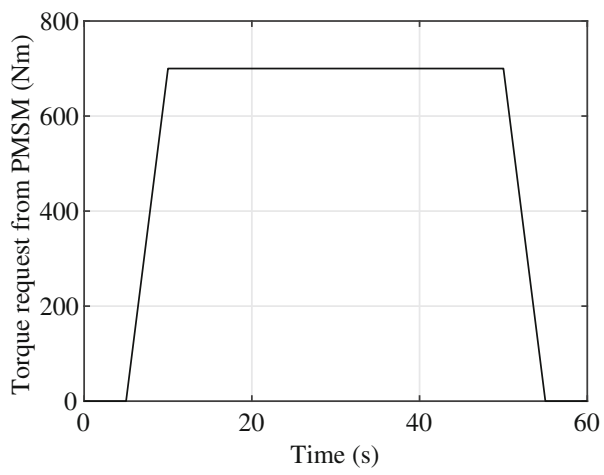

(c) PMSM torque profile

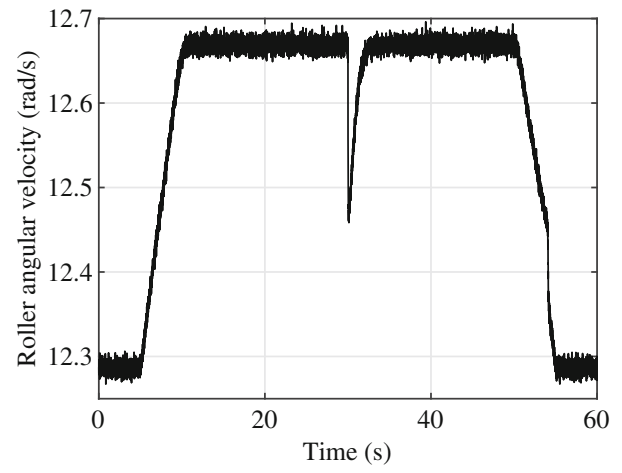

(b) Roller rotational speed

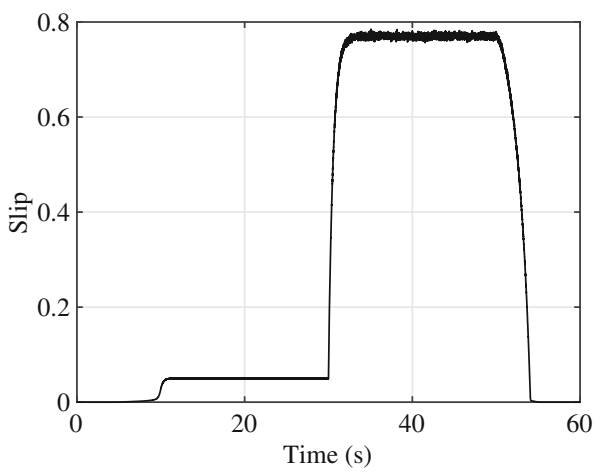

(d) Slip (creepage)

Fig. 14 Results of the mathematical model for the case when adhesion condition changes at $t=30 \mathrm{~s}$ from dry to wet

operational modes of the test stand. The control parameters of the PI controller are set as following: $K_{\mathrm{p}}=1000$ and $K_{\mathrm{i}}=4800$. The reference wheel slip is obtained from the results of the swarm intelligence-based adhesion estimation as provided in Table 5 .

Figure 15 shows the simulation results for the tram wheel test stand at $20 \mathrm{~km} / \mathrm{h}$ wheel speed and wet wheelroller surface condition. The driver torque request, the controller torque request and the PMSM torque response are illustrated in Fig. 15a. The corresponding wheel slip is provided in Fig. 15b. By analysing Fig. 15a, b, it is seen that the wheel slip is controlled effectively, where maximum $2.2 \%$ slip is observed. In addition, it can be seen in the slip curve provided in Fig. 15d that the wheel slip is stabilized where the maximum adhesion is observed. Figure $15 \mathrm{c}$ is the friction estimation results of the swarm intelligence-based estimation. Due to the characteristics of the estimator, the reference wheel slip is estimated 


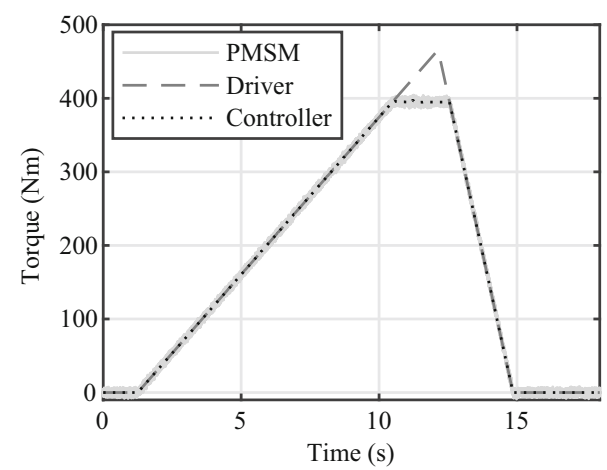

(a) Torque values

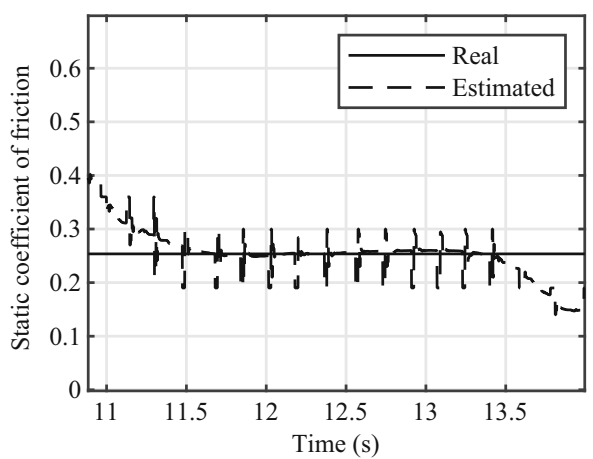

(c) Static friction coefficient

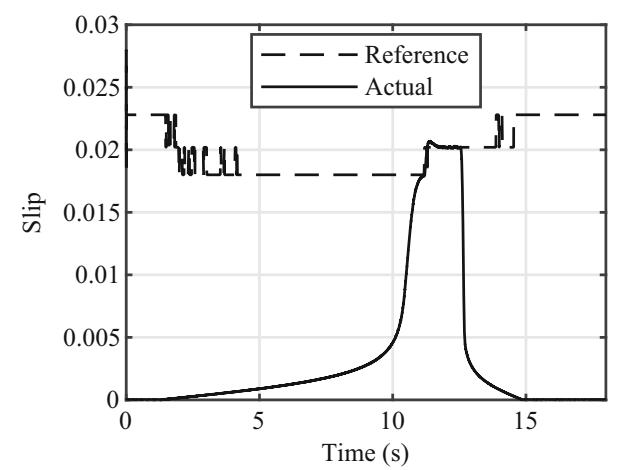

(b) Slip (creepage)

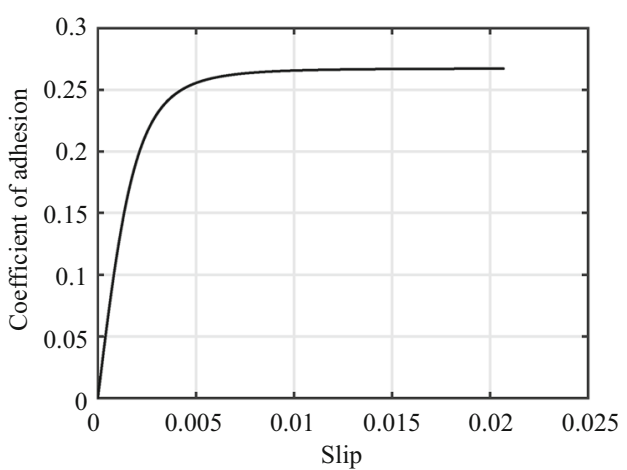

(d) Coefficient of adhesion

Fig. 15 Simulation results for PI wheel slip controller with swarm intelligence-based adhesion estimation at $20 \mathrm{~km} / \mathrm{h}$ and under wet wheel-roller surface condition

correctly when the wheel slip is higher than $1 \%$. Since the lowest threshold value for the wheel slip is $1.5 \%$, the controller is not affected by the reference slip fluctuations.

The simulation results of the controller at $20 \mathrm{~km} / \mathrm{h}$ and with the steady grease contaminant are shown in Fig. 16. Figure 16a presents the torque requests and PMSM torque response. The input torques and output torque are lower compared to the wet case since the lower friction condition exists. The resultant wheel slip is presented in Fig. 16b. It could be seen that the controller stabilizes the wheel slip at the reference value $(2.28 \%)$ in a very short time. Figure $16 \mathrm{~d}$ demonstrate the effectiveness of the controller in terms of the utilization of the adhesion. It should be noted that the swarm intelligence-based adhesion estimation provides better results compared to the wet case in terms of the determination of the reference wheel slip as illustrated in Fig. 16a, b.

Figure 17 shows the simulation results for the proposed control algorithm at $5 \mathrm{~km} / \mathrm{h}$ and with the wet wheel-roller surface condition. By analysing the results obtained in Fig. $17 \mathrm{a}, \mathrm{b}$, it is possible to see that the controller shows stable results in terms of slip control. The wheel slip is controlled effectively at $2 \%$ without any overshoot.
Furthermore, the controller provided optimum utilization of the adhesion by stabilizing the wheel slip at the reference value that is determined by results of estimated friction condition shown in Fig. 17c.

The simulation results of the proposed method at $5 \mathrm{~km} / \mathrm{h}$ and steady grease wheel-roller surface contaminant are provided in Fig. 18. It is observed from Fig. 19a, b that when the wheel slip exceeds the reference value, the controller stops torque increase and stabilize the wheel slip at $2.28 \%$. There is no significant overshoot observed in the wheel slip result. Moreover, the traction performance of the PMSM is improved with maintaining the adhesion at the peak of the slip curve. Similar to the previous results, the swarm intelligence-based adhesion estimation provides correct estimation, during the period when the controller is activated to prevent wheel slip.

Lastly, results for a case, which adhesion condition changes from dry to wet, are given in Fig. 19. In this case, generated measurements are used unlike the previous application cases. Gaussian noise is added up to the wheel and roller speed measurements. To show the system behaviour for noisy measurements, the moving average filter used in previous cases is not considered. Due to this 


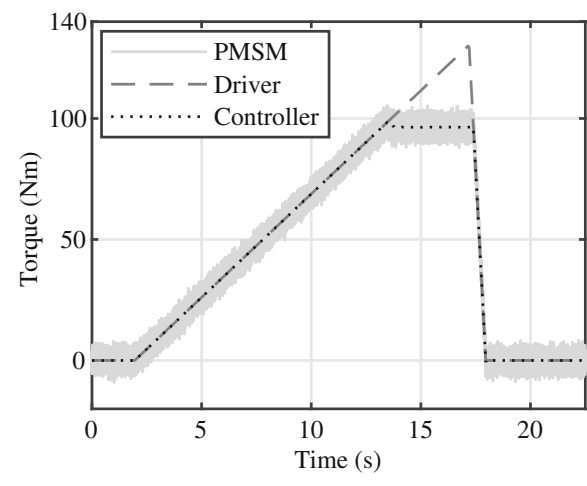

(a) Torque values

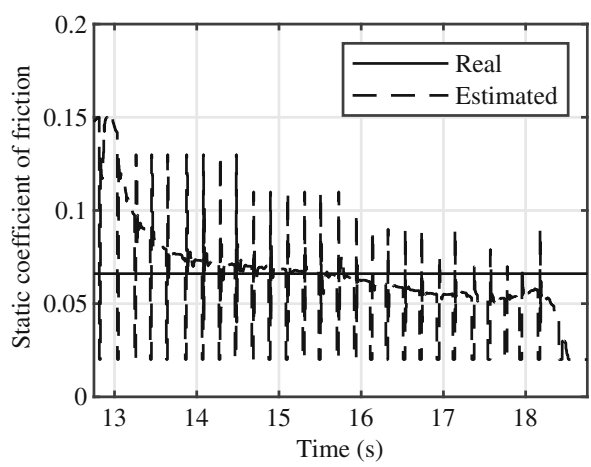

(c) Static friction coefficient

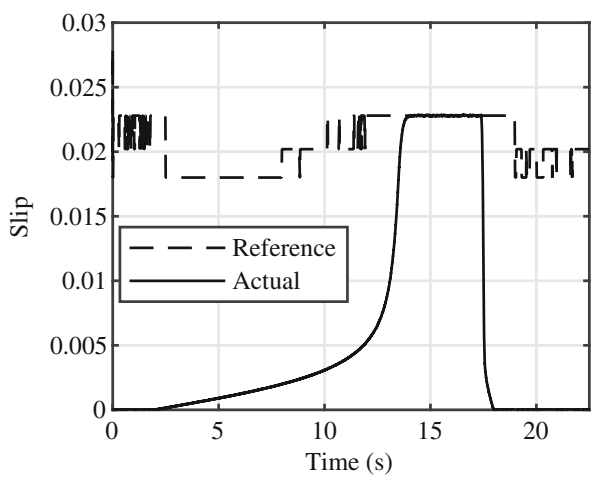

(b) Slip (Creepage)

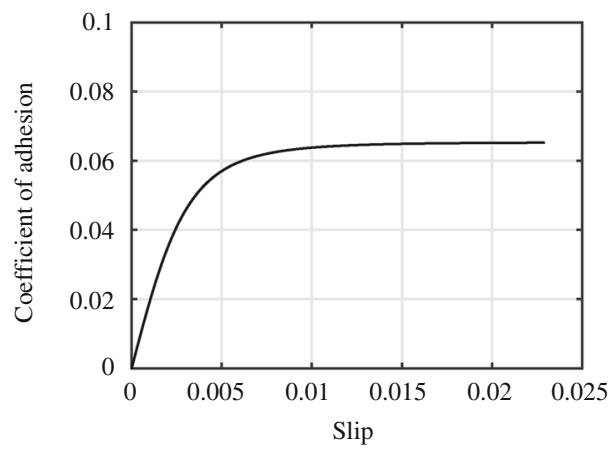

(d) Coefficient of adhesion

Fig. 16 Simulation results for PI wheel slip controller with swarm intelligence-based adhesion estimation at $20 \mathrm{~km} / \mathrm{h}$ and under greasy wheelroller surface condition

fact that estimation results highly fluctuates and it can be seen in Fig. 19c. Nevertheless, it is obvious that the average of these estimation results represent the actual friction coefficient. In this noisy measurement case, it can be seen that controller is also stable. In previous application cases, a moving average filter is a solution to the noisy measurements. Another solution could be to use a state filter (e.g. Kalman filter) which can further enhance the results.

The experimental test stand data acquisition device records the data with $200 \mathrm{~Hz}$ frequency. On the other hand, the control action of the wheel slip controller is limited with $25 \mathrm{~Hz}$. Simulations are carried out by using Matlab ${ }^{\circledR}$ on an MSI ${ }^{\circledR}$ GP72QF Leopard Pro laptop with a $2.8 \mathrm{GHz}$ dual-core Intel ${ }^{\circledR}$ Core $^{\mathrm{TM}}$ i7-7700HQ processor and $8 \mathrm{~GB}$ of RAM. Step time is set as $20 \mu$ s for simulation. The decision of the step time is due to the mathematical model of the electrical components. It is found out that the higher step times cause high amplitude vibrations on the torque output of the PMSM and AM. The action of the controller is limited with $25 \mathrm{~Hz}$ similar to the built-in controller of the experimental test stand. The simulation of a $17.355 \mathrm{~s}$ of experiment takes $30.17 \mathrm{~s}$. In practical application, the proposed control method can work faster since the output of the electrical components are not calculated but measured. Moreover, the simulation is carried out by Matlab ${ }^{\circledR}$ which is a high-level language. The computation time can be significantly reduced by using low-level languages such as $\mathrm{C}$ and $\mathrm{C}++$. Furthermore, multiprocessor system-onchip methodologies are available, and it is possible to realize such mathematical models for rail vehicles by using parallel processing. Thus, the methodology proposed in our work can be implemented in real time by considering multiprocessor systems and low-level languages. A recent study [60] discussed how such models for roller-rigs can be rearranged to work in real time. Same conclusion in [60] is valid also for this study.

The proposed control algorithm in this study is especially suitable for vehicles with motorized independently rotating wheels (i.e. IRW). The main problem for these vehicles is that their curving ability and stability is worse than the ones with solid axle wheelsets due to lack of yaw moments and restoring lateral forces. In order to overcome this issue, several controllers are proposed for IRW in the literature [61-64]. Either active elements [61, 63] or individual torque control for wheels $[62,64]$ are considered for this purpose. In addition, integration of both individual 


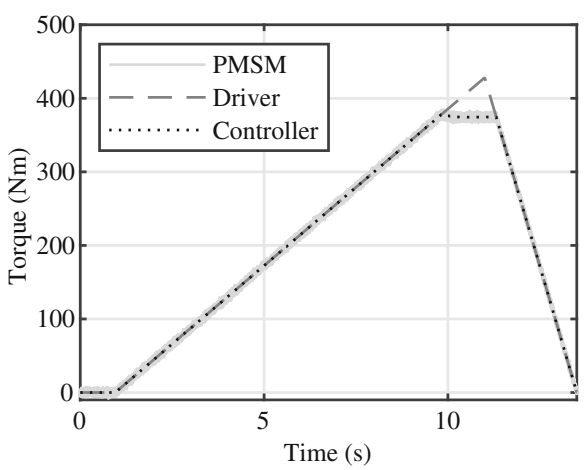

(a) Torque values

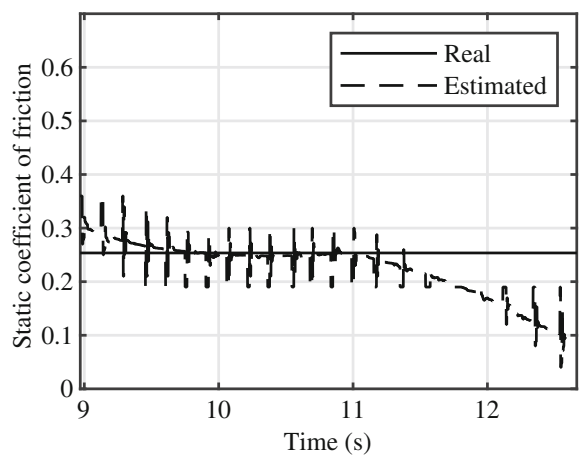

(c) Static friction coefficient

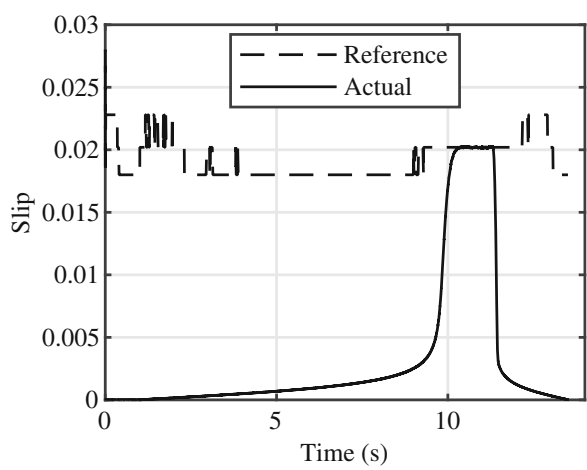

(b) Slip (creepage)

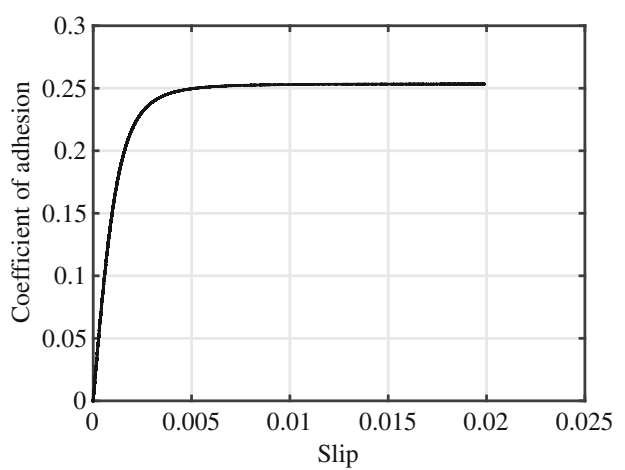

(d) Coefficient of adhesion

Fig. 17 Simulation results for PI wheel slip controller with swarm intelligence-based adhesion estimation at $5 \mathrm{~km} / \mathrm{h}$ and under wet wheel-roller surface condition

torque control and active elements was investigated [61]. To provide required stability and curve negotiation ability for such vehicles, the proposed slip controller can be considered here along with these controllers. If there is insufficient adhesion to apply required torque, then, the slip controller limits the torque. However, when used along with the proposed controller, such individual torque controllers can adjust the torque values of other wheels based on speed or torque difference of left and right motors $[61,63,64]$.

\section{Conclusions}

The PI wheel slip controller with swarm intelligence-based adhesion estimation has been proposed in this study. The performance of the proposed controller has been verified by a mathematical model of a tram wheel test stand. The simulations are carried out for wet and greasy wheel-roller surface conditions. Furthermore, to investigate the effect of speed, two speeds of $5 \mathrm{~km} / \mathrm{h}$ and $20 \mathrm{~km} / \mathrm{h}$ were selected to simulate the operational modes of the test stand. The obtained results show that the proposed controller provides an effective wheel slip control performance for both wet and greasy surface conditions. Furthermore, almost similar results are obtained at $5 \mathrm{~km} / \mathrm{h}$ and $20 \mathrm{~km} / \mathrm{h}$. The controller provides an improvement in the traction performance of the PMSM by stabilizing the wheel slip at the peak of the slip curve which helps to establish optimum utilization of the adhesion.

The fluctuations are observed in the selection of the reference wheel slip. Due to the persistency of excitation characteristic of the parameter estimation for the swarm intelligence-based adhesion estimation, the friction during the low wheel slip cannot be estimated correctly. The provided estimation result causes the fluctuation in reference slip value. However, the wheel slip controller is activated during relatively high wheel slip, when enough torque (i.e. excitation) is exerted on the system. Therefore, when the wheel slip results of the simulations are analysed, it could be seen that the optimal reference slip value is provided when the controller is activated.

The simulation results have similarities with the previous study, which is about a wheel slip control method based on adaptive sliding mode control [20]. Both control methods have effective performances in the stabilization of 


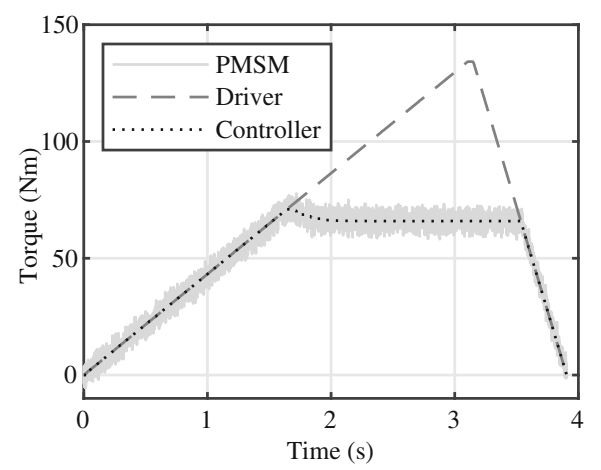

(a) Torque values

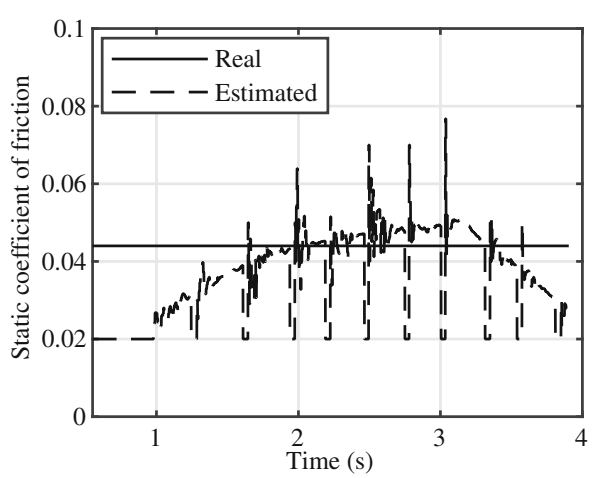

(c) Static friction coefficient

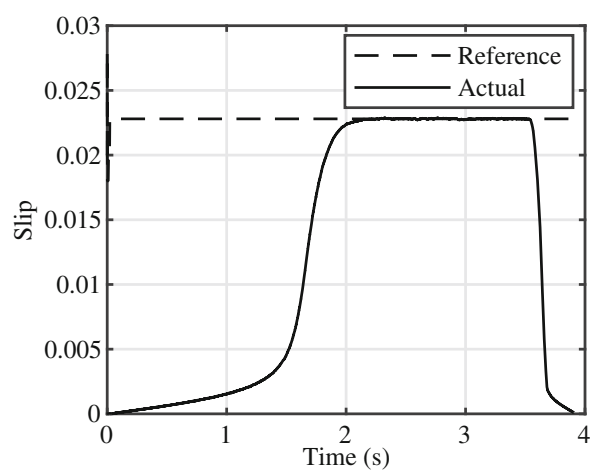

(b) Slip (creepage)

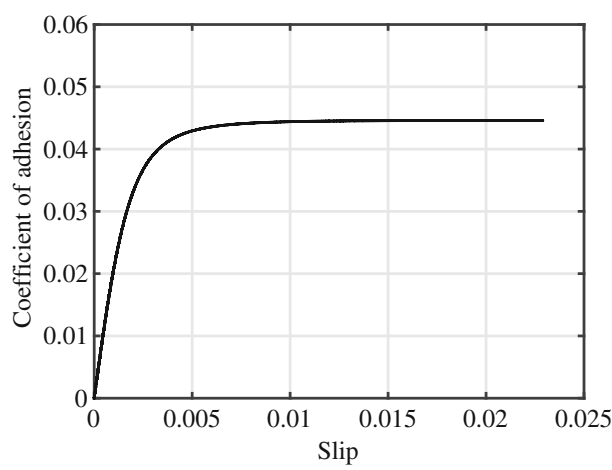

(d) Coefficient of adhesion

Fig. 18 Simulation results for PI wheel slip controller with swarm intelligence-based adhesion estimation at $5 \mathrm{~km} / \mathrm{h}$ and under greasy wheelroller surface condition

the wheel slip. Due to optimal selection of reference slip value, the PI controller with swarm intelligence-based adhesion estimation in this study ensures better adhesion utilization. In addition, it is not required to measure the adhesion force to employ the control torque. However, the controller has poor performance when the reference slip value is selected in the unstable part of the slip curve.
In the future work, authors plan to combine the swarm intelligence-based method with an unscented Kalman filter which is used for friction estimation [32]. Thus, the estimation results can be enhanced significantly by considering a state filter. In order to combine two methods, the approach proposed in [65] will be considered. 


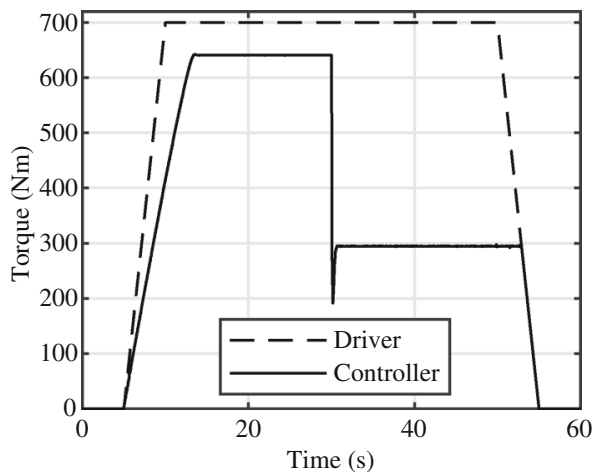

(a) Torque values

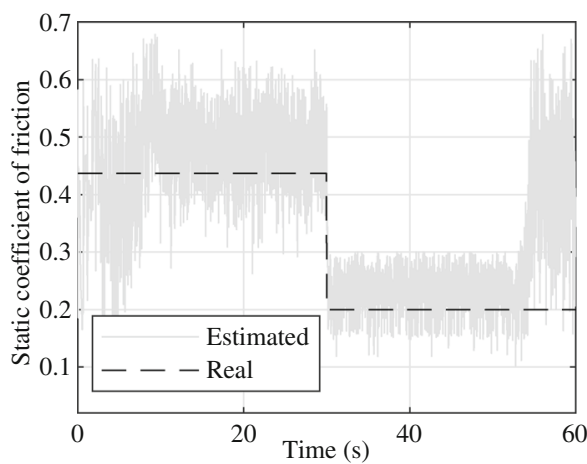

(c) Static friction coefficient

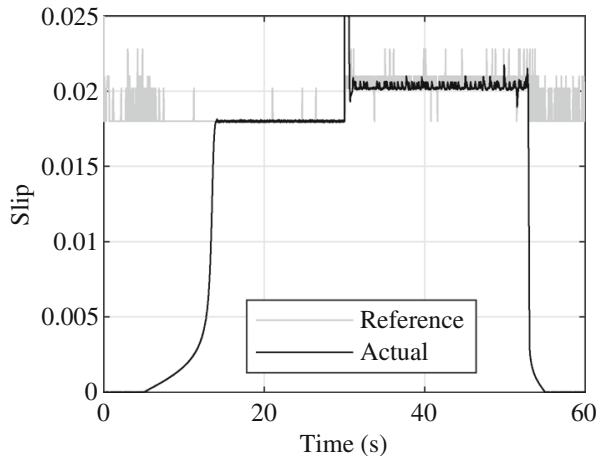

(b) Slip (creepage)

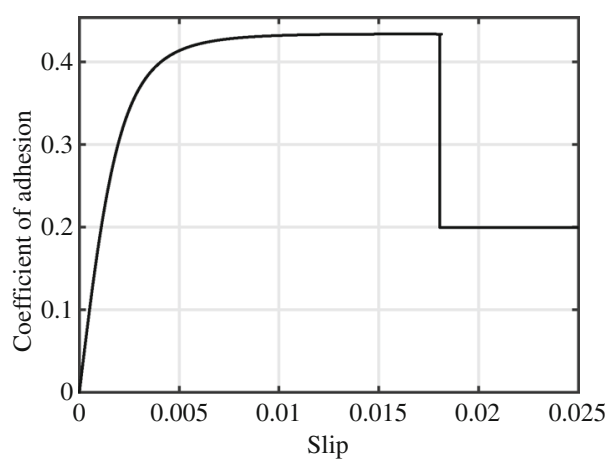

(d) Coefficient of adhesion

Fig. 19 Simulation results for PI wheel slip controller with swarm intelligence-based adhesion estimation at $20 \mathrm{~km} / \mathrm{h}$, switching from dry to wet conditions at $t=30 \mathrm{~s}$

Acknowledgements The authors are grateful to doc. Ing. Petr Voltr, Ph.D. and doc. Ing. Michael Lata from University of Pardubice, Czechia for their comments and support for this work. Second author would like to thank prof. Ing. Jaroslav Novák, CSc. from University of Pardubice, Czechia for his help and patience during the measurements from asynchronous motor.

Open access This article is distributed under the terms of the Creative Commons Attribution 4.0 International License (http:// creativecommons.org/licenses/by/4.0/), which permits unrestricted use, distribution, and reproduction in any medium, provided you give appropriate credit to the original author(s) and the source, provide a link to the Creative Commons license, and indicate if changes were made.

Funding This work is supported by University of Pardubice, Czechia, Eskisehir Technical University, Turkey, and Newcastle University, United Kingdom.

\section{References}

1. Pichlík P (2018) Strategy of railway traction vehicles wheel slip control. Czech Technical University, Prague

2. Frylmark D, Johnsson S (2003) Automatic slip control for railway vehicles. Dissertation, Linköping University

3. Zirek A (2019) Anti-slip control of traction motor of rail vehicles. Ph.d thesis, University of Pardubice, Pardubice
4. Chen H, Ban T, Ishida $M$ et al (2002) Adhesion between rail/ wheel under water lubricated contact. Wear 253(1-2):75-81

5. Gallardo-Hernandez EA, Lewis R (2008) Twin disc assessment of wheel/rail adhesion. Wear 265(9-10):1309-1316

6. Lewis R, Dwyer-Joyce R, Lewis S et al (2012) Tribology of the wheel-rail contact: the effect of third body materials. Int J Railw Technol 1(1):167-194

7. Li Z, Arias-Cuevas O, Lewis R et al (2009) Rolling-sliding laboratory tests of friction modifiers in leaf contaminated wheel-rail contacts. Tribol Lett 33(2):97

8. Polach O (2005) Creep forces in simulations of traction vehicles running on adhesion limit. Wear 258(7-8):992-1000

9. Voltr P, Lata M (2015) Transient wheel-rail adhesion characteristics under the cleaning effect of sliding. Veh Syst Dyn 53(5):605-618

10. Bosso N, Magelli M, Zampieri N (2019) Investigation of adhesion recovery phenomenon using a scaled roller-rig. Veh Syst Dyn. https://doi.org/10.1080/00423114.2019.1677922

11. Meacci M, Shi Z, Butini E et al (2019) A local degraded adhesion model for creep forces evaluation: an approximate approach to the tangential contact problem. Wear 440-441:203084

12. Meacci M, Shi Z, Butini E et al (2020) A railway local degraded adhesion model including variable friction, energy dissipation and adhesion recovery. Veh Syst Dyn. https://doi.org/10.1080/ 00423114.2020.1775266

13. Shrestha S, Spiryagin M, Wu Q (2019) Friction condition characterization for rail vehicle advanced braking system. Mech Syst Signal Process 134:106324

14. Park DY, Kim MS, Hwang DH, et al (2001) Hybrid re-adhesion control method for traction system of high-speed railway. In: 
ICEMS'2001, proceedings of the fifth international conference on electrical machines and systems (iEEE Cat. No. 01EX501), vol 2. IEEE, pp 739-742

15. Ryoo H, Kim S, Rim G, et al (2003) Novel anti-slip/slide control algorithm for Korean high-speed train. In: IECON'03. 29th annual conference of the ieee industrial electronics society (IEEE Cat. No. 03CH37468), vol 3. IEEE, pp 2570-2574

16. Yamashita M, Watanabe $\mathrm{T}$ (2005) Readhesion control method without speed sensors for electric railway vehicles. Q Rep RTRI 46(2):85-89

17. Yamashita M, Soeda T (2015) Anti-slip re-adhesion control method for increasing the tractive force of locomotives through the early detection of wheel slip convergence. In: 2015 17th European conference on power electronics and applications (EPE'15 ECCE-Europe). IEEE, pp 1-10

18. Mei T, Hussain I (2010) Detection of wheel-rail conditions for improved traction control. In: IET Conference on railway traction systems (RTS 2010). IET, pp 1-6

19. Wang S, Xiao J, Huang J et al (2016) Locomotive wheel slip detection based on multi-rate state identification of motor load torque. J Franklin Inst 353(2):521-540

20. Zirek A, Voltr P, Lata M et al (2018) An adaptive sliding mode control to stabilize wheel slip and improve traction performance. Proce Inst Mech Eng Part F J Rail Rapid Transit 232(10):2392-2405

21. Kim JS, Park SH, Choi JJ, et al (2011) Adaptive sliding mode control of adhesion force in railway rolling stocks. In: Sliding mode control. IntechOpen, pp 385-408

22. Spiryagin M, Sun YQ, Cole C et al (2011) Development of traction control for hauling locomotives. J Syst Des Dyn 5(6): 1214-1225

23. Chang CY, Kim JM, Kim YH (2015) A design of prototype 1c2m railway vehicle propulsion control system considering slip reduction of traction motor. J Electr Eng Technol 10(1):429-435

24. Ohishi K, Hata T, Sano T et al (2009) Realization of anti-slip/skid re-adhesion control for electric commuter train based on disturbance observer. IEEJ Trans Electr Electron Eng 4(2):199-209

25. Mei T, Yu J, Wilson D (2009) A mechatronic approach for effective wheel slip control in railway traction. Proc Inst Mech Eng Part F J Rail Rapid Transit 223(3):295-304

26. Çimen MA, Ararat Ö, Söylemez MT (2018) A new adaptive slipslide control system for railway vehicles. Mech Syst Signal Process 111:265-284

27. Spiryagin $M$, Wolfs $P$, Cole $C$ et al (2017) Influence of ac system design on the realisation of tractive efforts by high adhesion locomotives. Veh Syst Dyn 55(8):1241-1264

28. Shrestha S, Wu Q, Spiryagin M (2019) Review of adhesion estimation approaches for rail vehicles. Int $\mathbf{J}$ Rail Transp 7(2):79-102

29. Spiryagin M, Cole C, Sun YQ (2014) Adhesion estimation and its implementation for traction control of locomotives. Int J Rail Transp 2(3):187-204

30. Wei L, Zeng J, Wu P et al (2014) Indirect method for wheel-rail force measurement and derailment evaluation. Veh Syst Dyn 52(12):1622-1641

31. Hussain I, Mei T, Ritchings R (2013) Estimation of wheel-rail contact conditions and adhesion using the multiple model approach. Veh Syst Dyn 51(1):32-53

32. Onat A, Voltr P, Lata M (2017) A new friction condition identification approach for wheel-rail interface. Int J Rail Transp 5(3): $127-144$

33. Zhao Y, Liang B (2013) Re-adhesion control for a railway single wheelset test rig based on the behaviour of the traction motor. Veh Syst Dyn 51(8):1173-1185
34. Hubbard PD, Ward C, Dixon R et al (2014) Models for estimation of creep forces in the wheel/rail contact under varying adhesion levels. Veh Syst Dyn 52(sup1):370-386

35. Malvezzi M, Pugi L, Papini S et al (2013) Identification of a wheel-rail adhesion coefficient from experimental data during braking tests. Proc Inst Mech Eng Part F J Rail Rapid Transit 227(2):128-139

36. Onat A, Voltr P (2017) Swarm intelligence based multiple model approach for friction estimation at wheel-rail interface. In: 5th International symposium on engineering, artificial intelligence and applications, ISEAIA 2017. pp 187-194

37. Onat A, Voltr P (2019) Velocity measurement-based friction estimation for railway vehicles running on adhesion limit: swarm intelligence-based multiple models approach. J Intell Transp Syst. https://doi.org/10.1080/15472450.2018.1542305

38. Onat A, Kayaalp BT (2018) Normal load estimation by using a swarm intelligence based multiple models approach. In: Fourth international symposium on railway systems engineering, ISERSE 2018. pp 489-496

39. Onat A, Kayaalp BT (2019) A novel methodology for dynamic weigh in motion system for railway vehicles with traction. IEEE Trans Veh Technol 68(11):10545-10558

40. Wu Q, Cole C, McSweeney T (2016) Applications of particle swarm optimization in the railway domain. Int $\mathrm{J}$ Rail Transp 4(3):167-190

41. Onat A (2017) Estimation of states and parameters from dynamic response of wheelset. Ph.d. thesis, University of Pardubice, Pardubice

42. Trummer G, Buckley-Johnstone L, Voltr P et al (2017) Wheelrail creep force model for predicting water induced low adhesion phenomena. Tribol Int 109:409-415

43. Onat A, Voltr P, Lata M (2018) An unscented kalman filter-based rolling radius estimation methodology for railway vehicles with traction. Proc Inst Mech Eng Part F J Rail Rapid Transit 232(6):1686-1702

44. Zirek A, Voltr P, Lata M (2019) Validation of an anti-slip control method based on the angular acceleration of a wheel on a roller rig. Proc Inst Mech Eng Part F J Rail Rapid Transit 234(9):1029-1040

45. Voltr P, Lata M, Černỳ O (2012) Measuring of wheel-rail adhesion characteristics at a test stand. Eng Mech 181:1543-1553

46. Doleček R, Novák J, Černỳ O (2009) Traction permanent magnet synchronous motor torque control with flux weakening. Radioengineering 18(4):601-605

47. Simanek J, Novak J, Cerny O (2008) Foc and flux weakening for traction drive with permanent magnet synchronous motor. In: IEEE international symposium on industrial electronics. IEEE, pp 753-758

48. Qian P, Zhang Y (2011) Study on hysteresis current control and its applications in power electronics. In: $\mathrm{Hu}$ W (ed) Electronics and signal processing. Springer, Berlin, pp. 889-895

49. Simanek J, Novak J, Dolecek R et al (2007) Control algorithms for permanent magnet synchronous traction motor. In: EUROCON 2007-the international conference on" computer as a tool. IEEE. pp 1839-1844

50. Zhang W, Chen J, Wu X et al (2002) Wheel/rail adhesion and analysis by using full scale roller rig. Wear 253(1-2):82-88

51. Mudi RK, Dey C, Lee TT (2008) An improved auto-tuning scheme for pi controllers. ISA Trans 47(1):45-52

52. Ang KH, Chong G, Li Y (2005) Pid control system analysis, design, and technology. IEEE Trans Control Syst Technol 13(4):559-576

53. Eberhart R, Kennedy J (1995) A new optimizer using particle swarm theory. In: MHS'95. Proceedings of the sixth international symposium on micro machine and human science. IEEE, pp 39-43 
54. Zhang J, Zhu X, Wang Y et al (2018) Dual-environmental particle swarm optimizer in noisy and noise-free environments. IEEE Trans Cybern 49(6):2011-2021

55. Bansal JC, Singh P, Saraswat M (2011) Inertia weight strategies in particle swarm optimization. In: Third world congress on nature and biologically inspired computing. IEEE 2011, pp 633-640

56. Shahzad F, Masood S, Khan NK (2014) Probabilistic oppositionbased particle swarm optimization with velocity clamping. Knowl Inf Syst 39(3):703-737

57. Binkley KJ, Hagiwara M (2008) Balancing exploitation and exploration in particle swarm optimization: velocity-based reinitialization. Inf Media Technol 3(1):103-111

58. Bosso N, Zampieri N (2013) Real-time implementation of a traction control algorithm on a scaled roller rig. Veh Syst Dyn 51(4):517-541

59. Onat A, Voltr P (2020) Particle swarm optimization based parametrization of adhesion and creep force models for simulation and modelling of railway vehicle systems with traction. Simul Model Pract Theory 99:102026
60. Shrestha S, Spiryagin M, Wu Q (2020) Real-time multibody modeling and simulation of a scaled bogie test rig. Railw Eng Sci 28(2):146-159

61. Perez J, Busturia JM, Mei T et al (2004) Combined active steering and traction for mechatronic bogie vehicles with independently rotating wheels. Ann Rev Control 28(2):207-217

62. Oh YJ, Lee JK, Liu HC et al (2019) Hardware-in-the-loop simulation for active control of tramcars with independently rotating wheels. IEEE Access 7:71252-71261

63. Liu X, Goodall R, Iwnicki S (2020) Active control of independently-rotating wheels with gyroscopes and tachometers-simple solutions for perfect curving and high stability performance. Veh Syst Dyn 1-16

64. Cho Y (2020) Verification of control algorithm for improving the lateral restoration performance of an independently rotating wheel type railway vehicle. Int J Precis Eng Manuf

65. Onat A (2019) A novel and computationally efficient joint unscented kalman filtering scheme for parameter estimation of a class of nonlinear systems. IEEE Access 7:31634-31655 